\title{
TU/e EmonONEN

\section{Atomic and molecular oxygen as chemical precursors in the oxidation of ammonia by copper}

\section{Citation for published version (APA):}

Neurock, M., Santen, van, R. A., Biemolt, W., \& Jansen, A. P. J. (1994). Atomic and molecular oxygen as chemical precursors in the oxidation of ammonia by copper. Journal of the American Chemical Society, 116(15), 6860-6872. https://doi.org/10.1021/ja00094a046

DOI:

10.1021/ja00094a046

Document status and date:

Published: 01/01/1994

\section{Document Version:}

Publisher's PDF, also known as Version of Record (includes final page, issue and volume numbers)

\section{Please check the document version of this publication:}

- A submitted manuscript is the version of the article upon submission and before peer-review. There can be important differences between the submitted version and the official published version of record. People interested in the research are advised to contact the author for the final version of the publication, or visit the $\mathrm{DOI}$ to the publisher's website.

- The final author version and the galley proof are versions of the publication after peer review.

- The final published version features the final layout of the paper including the volume, issue and page numbers.

Link to publication

\section{General rights}

Copyright and moral rights for the publications made accessible in the public portal are retained by the authors and/or other copyright owners and it is a condition of accessing publications that users recognise and abide by the legal requirements associated with these rights.

- Users may download and print one copy of any publication from the public portal for the purpose of private study or research.

- You may not further distribute the material or use it for any profit-making activity or commercial gain

- You may freely distribute the URL identifying the publication in the public portal.

If the publication is distributed under the terms of Article 25fa of the Dutch Copyright Act, indicated by the "Taverne" license above, please follow below link for the End User Agreement:

www.tue.nl/taverne

Take down policy

If you believe that this document breaches copyright please contact us at:

openaccess@tue.nl

providing details and we will investigate your claim. 


\title{
Atomic and Molecular Oxygen as Chemical Precursors in the Oxidation of Ammonia by Copper
}

\author{
M. Neurock, "t R. A. van Santen, W. Biemolt, and A. P. J. Jansen \\ Contribution from the Schuit Institute of Catalysis, Laboratory of Inorganic Chemistry and \\ Catalysis, Eindhoven University of Technology, P.O. Box 513, 5600 MB Eindhoven, \\ The Netherlands
}

Received October 18, 1993. Revised Manuscript Received May 2, $1994^{\circ}$

\begin{abstract}
The role of atomic and molecular oxygen precursors in the overall catalytic cycle for ammonia dissociation is analyzed using first-principle density functional calculations. Adsorption energies for ammonia, molecular oxygen, $\mathrm{NH}_{x}, \mathrm{NO}$, and various intermediates and adatoms were computed from geometry optimized calculations on the model $\mathrm{Cu}(8,3)$ cluster of the $\mathrm{Cu}(111)$ surface. Reported values systematically underpredict experimental adsorption energies by $30 \mathrm{~kJ} / \mathrm{mol}$ due to the finite cluster size. Attractive and repulsive lateral interactions were important in accessing accurate adsorption energies. Atomic oxygen enhances $\mathrm{N}-\mathrm{H}$ bond activation; however, it also acts to poison active surface sites and inhibit ammonia dissociation kinetics. Transient molecular oxygen adsorbs weakly in both parallel $(-17 \mathrm{~kJ} / \mathrm{mol})$ and perpendicular orientations $(-10 \mathrm{~kJ} / \mathrm{mol})$ to the surface. Parallel adsorption appears to be a precursor for oxygen dissociation, whereas perpendicular adsorption is the precursor for ammonia dissociation. The mechanism in which hydrogen atoms are abstracted sequentially to form $O O H^{*}$ intermediate $\left[E^{*}\right.$ (apparent) $\left.=0 \mathrm{~kJ} / \mathrm{mol}\right]$ is favored over that in which two hydrogens are simultaneously transferred to form water directly [ $E^{*}$ (apparent) $=+67 \mathrm{~kJ} / \mathrm{mol}$ ] The nonactivated transient molecular path in which hdyrogen is abstracted sequentially is the most favored of all of the four paths studied. In light of the experimental $\mathrm{O}_{2}$ dissociation energy over $\mathrm{Cu}(111)$, transient $\mathrm{O}_{2}$ is more likely than "hot" atomic oxygen as the dominant chemical precursor for ammonia dissociation. Subsequent dissociation of the $\mathrm{NH}_{x}$ fragments lead to $\mathrm{N}^{*}$. While enthalpic considerations favor recombinative desorption of $\mathrm{N}_{2}$, at reaction conditions the MARI is atomic oxygen thus making the recombinative desorption of NO more likely reaction path.
\end{abstract}

\section{Introduction}

Both atomic and molecular oxygen surface species have been speculated as governing chemical precursors for several important transition metal catalyzed reactions. On silver, for example, weakly bound atomic oxygen which is stabilized by subsurface oxygen was cited as the dominant precursor in ethylene epoxidation, ${ }^{1-3}$ whereas molecular oxygen was found to control the oxidation of $\mathrm{SO}_{2}$ and $\mathrm{CO}_{4}^{4}$ In addition, there has even been support for both oxygen species in mediating the same catalytic reaction paths. Roberts et al., for example, have cited atomic and molecular precursors as controlling the oxidation of ammonia over $\mathrm{Mg},{ }^{5-8} \mathrm{Zn},{ }^{9,10}$ and $\mathrm{Cu} .{ }^{11-14}$ Clearly, the role of both atomic and molecular oxygen species as precursors is of considerable importance in understanding a significant spectrum of different selective oxidation reaction pathways.

\footnotetext{
${ }^{\dagger}$ Present address: DuPont Central Research and Development, Experimental Station, Wilmington, DE 19880-0262.

- Abstract published in Advance ACS Abstracts, July 1, 1994.

(1) van den Hoek, P. J.; Baerends, E. J.; van Santen, R. A. J. Phys. Chem. $1989,93,6469-6475$.

(2) van Santen, R. A. J. Mol. Catal. 1989, 54, 288-300.

(3) Zonnevylle, M. C.; Hoffmann, R. H.; van de Hoek, P. J.; van Santen, R. A. Surf. Sci. 1989, 223, 233.
}

(4) Capote, A. J.; Roberts, J. T.; Madix, R. J. Surf. Sci. 1989, 209, L151L156.

(5) Au, C. T.; Roberts, M. W. Nature 1986, 319, 206.

(6) Au, C.; Roberts, M. W. J. Chem. Soc., Faraday Trans. 1987, 83, 2047-2059.

(7) Blake, P. G.; Roberts, M. W. Catal. Lett. 1989, 3, 379-404

(8) Roberts, M. W. J. Mol. Catal. 1992, 74, 11.

(9) Carley, A. F.; Yan, S.; Roberts, M. W. J. Chem. Soc., Faraday Trans. 1990, 86, 2701

(10) Carley, A. F.; Roberts, M. W.; Tomellini, M. J. Chem. Soc., Faraday Trans. 1991, 87, (21), 3563-3567.

(11) Afsin, B.; Davies, P. R.; Pashuski, A.; Roberts, M. W. Surf. Sci. Lett. 1991, 259, L724-L728.

(12) Afsin, B.; Davies, P. R.; Pashusky, A.; Roberts, M. W.; Vincent, D Surf. Sci. 1993, 284, 109-120.

(13) Au, C. T.; Roberts, M. W. Chem. Phys. Lett. 1980, 74 (3), $472-474$.

(14) Boronin, A.; Pashusky, A.; Roberts, M. W. Catal. Lett. 1992, 16, $345-350$.

$0002-7863 / 94 / 1516-6860 \$ 04.50 / 0$
The transient nature of chemical precursors, however, makes it difficult to experimentally resolve their role in the mechanism. For example, oxygen has been shown to both activate strong nitrogen-, sulfur-, and carbon-hydrogen bonds on transition metal surfaces ${ }^{13,31}$ and also inhibit dissociation. ${ }^{11,12,14}$ While it is generally agreed that the formation of strong chemisorbed atomic oxygen overlayers poisons active surface sites and is responsible for inhibition, the nature of the activation process is still unclear. In this work we present a theoretical analysis of the dissociation of ammonia over copper and elucidate the role of both adsorbed atomic and molecular oxygen species. We first provide a short background of the experimental literature on ammonia oxidation before outlining the specifics of this study.

Roberts and his group have experimentally investigated the role of oxygen in the dissociation of ammonia on both $\mathrm{Cu}(110)^{11,12}$ and $\mathrm{Cu}(111) .13,14 \mathrm{On} \mathrm{Cu}(110)$, they found that both the activity and the selectivity toward different $\mathbf{N H}_{x}$ products were highly sensitive to the reaction conditions and to the order in which the reactants were introduced to the surface. For example, when oxygen was preadsorbed on the surface, a very slow exchange of oxygen and ammonia was required prior to any subsequent dissociation of ammonia to different $\mathrm{NH}_{x}$ species. The surface amide $\left(\mathrm{NH}_{2}{ }^{*}\right)$ was favored at low temperatures and coverages, whereas the surface imide $\left(\mathrm{NH}^{*}\right)$ and surface nitrogen $\left(\mathrm{N}^{*}\right)$ were favored at higher temperatures and coverages. The activity was attributed to only a small fraction of the preadsorbed oxygen species. The remaining oxygen was thought to poison surface and inhibit the kinetics.

When oxygen and ammonia were coadsorbed (in a regime of excess ammonia), however, there was rapid dissociation of the ammonia with a high selectivity for $\mathrm{NH}^{*}$ formation. The initial speculation was that a molecularly adsorbed transient oxygen precursor, similar to that which was found on $\mathrm{Zn}(001)$ surface,, 10 was responsible for the chemistry.

(15) Brune, H.; Wintterlin, J.; Behm, R. J.; Ertl, G. Phys. Rev. Lett. 1992, 68,624 .

c 1994 American Chemical Society 
On $\mathrm{Cu}(111)$, Roberts and colleagues ${ }^{13,14}$ once again found that ammonia readily dissociates in the presence of oxygen. Based on their results and the ideas proposed by Ertl for the dissociation of oxygen on platinum, ${ }^{15}$ they suggested that the mechanism for the initial dissociation might be controlled by a "hot" transient atomic oxygen species. It is speculated that these species rapidly diffuse across the surface and abstract hydrogen from the coadsorbed ammonia before becoming thermally equilibrated with the surface. At high oxygen partial pressures, they found that the rate was inhibited by the presence of chemisorbed oxygen overlayers.

Clearly, the controlling chemistry in these systems and the role of oxygen is a complex function of competing elementary reaction steps. Both the overall catalytic cycle and details of the mechanism and activation barriers are, therefore, essential for a more complete and fundamental understanding of the operative chemistry. Herein, we report the results of a theoretical analysis of the mechanism of oxygen-assisted ammonia dissociation on model $\mathrm{Cu}$ clusters of the $\mathrm{Cu}(111)$ surface. We draw upon some of our previous results which were aimed at deducing (1) the electronic features responsible for the interaction of ammonia at various different adsorption sites on $\mathrm{Cu}(111)$ surface, ${ }^{16}(2)$ the effects of cluster size and fixed electronic core configurations on the computed ammonia adsorption energy, ${ }^{16}$ and (3) the role of chemisorbed atomic oxygen on the activation of the NH bond..$^{17,18}$

In this work we analyze the five following paths as plausible controlling mechanistic steps in the dissociation of ammonia in the presence of oxygen.

$$
\begin{aligned}
\mathrm{NH}_{3}(\mathrm{a})+\mathrm{O}(\mathrm{a}) & \rightarrow \mathrm{NH}_{2}(\mathrm{a})+\mathrm{OH}(\mathrm{a}) \\
\mathrm{NH}_{3}(\mathrm{a})+\mathrm{O}(\mathrm{a}) & \rightarrow \mathrm{NH}(\mathrm{a})+\mathrm{H}_{2} \mathrm{O}(\mathrm{g}) \\
\mathrm{NH}_{3}(\mathrm{a})+\mathrm{O}_{2}(\mathrm{a}) & \rightarrow \mathrm{NH}_{2}(\mathrm{a})+\mathrm{OOH}(\mathrm{a}) \\
\mathrm{NH}_{3}(\mathrm{a})+\mathrm{O}_{2}(\mathrm{a}) & \rightarrow \mathrm{NH}(\mathrm{a})+\mathrm{H}_{2} \mathrm{O}(\mathrm{g}) \\
\mathrm{NH}_{3}(\mathrm{a})+\mathrm{O}^{\mathrm{h}}(\mathrm{a}) & \rightarrow \mathrm{NH}(\mathrm{a})+\mathrm{H}_{2} \mathrm{O}(\mathrm{g})
\end{aligned}
$$

In the first two paths, chemisorbed atomic oxygen is proposed as being responsible for ammonia dissociation. In path 1 , a single $\mathrm{N}-\mathrm{H}$ bond is activated by the adsorbed oxygen, whereas in path 2 the ammonia is situated on the surface such that two N-H bonds can simultaneously be activated and water is formed directly. In paths 3 and 4 , molecular oxygen is considered to be active precursor responsible for the dissociation of ammonia. In path 3 , a single hydrogen is abstracted to form the $\mathrm{OOH}^{*}$ intermediate, whereas in path 4 two hydrogens are simultaneously transferred to form water. The final pathway is that which was proposed by Roberts, where a "hot" transient atomic oxygen surface species $\left(\mathrm{O}^{\mathrm{h}}\right)$ which has not been thermally equilibrated with the surface, controls $\mathrm{NH}$ bond activation. ${ }^{5-7,12,14}$ We used first-principle density functional calculations to analyze in detail the activation barriers and corresponding catalytic reaction cycles associated with the first four of these paths. Based on these results we speculate as to which is the dominant path and access the plausibility of the final "hot" oxygen-mediated path.

\section{Methods}

Density functional quantum chemical calculations were performed to determine gas phase formation, bond dissociation, adsorption, and activation energies. Nearly all of the results reported here were derived from the Amsterdam Density Function

(16) Biemolt, W.; van de Kerkhof, G. J. C. S.; Davies, P. R.; Jansen, A P. J.; van Santen, R. A. Chem. Phys. Lett. 1992, $188(5,6), 477-486$.

(17) Biemolt, W.; Jansen, A. P. J.; Neurock, M.; van de Kerkhof, G. J. C. S.; van Santen, R. A. Surf. Sci. 1993, 187, 183.

(18) van de Kerkhof, G. J. C. S.; Biemolt, W.; Jansen, A. P. J.; van Santen R. A. Surf. Sci. 1993, 284, 361-171.
(ADF) program of Baerends and co-worker. ${ }^{19-21}$ Some supplementary calculations of the transition barriers were determined by the DGauss program from Cray Research Inc. ${ }^{22}$ The main differences between these two methods are computational. The ADF program, for example, is based on Slater type orbitals, whereas DGauss utilizes Gaussian orbital basis sets. Adsorption energies for ammonia and other adsorbates computed from both programs were shown to be equivalent to within $\pm 10 \mathrm{~kJ} / \mathrm{mol}$. Both programs solve the Kohn-Sham one-electron equations and invoke the local density approximation by implementing the exchange correlation energy functional of Vosko-Wilk-Nusair. ${ }^{23}$ Nonlocal gradient corrections for the exchange and correlation terms were computed subsequent to both self-consistent-field (SCF) convergence and geometry optimization calculations and determined by the methods established by Becke ${ }^{24,25}$ and Perdew, ${ }^{26}$ respectively. All calculations reported here were performed using nonrelativistic, spin-unrestricted, frozen-core calculations. The basis sets used in both ADF and DGauss were of single- $\zeta$ quality for core orthogonalization and double- $\zeta$ for nitrogen oxygen and triple- $\zeta$ quality for copper with polarization functions included for all valence electrons. The exponential coefficients for the basis and fit functions used in the ADF calculations are reported in the Appendix and discussed in more detail elsewhere. ${ }^{16,18}$ The basis sets and fit functions used in the DGauss program were reported by Andzelm. ${ }^{22,27}$ In the ADF calculations the copper basis was frozen up to and including the $3 p$ core, whereas in nitrogen and oxygen the $1 \mathrm{~S}$ core was frozen, whereas in the DGauss calculations all electrons were explicitly included. The analytical gradient algorithms ${ }^{22,28}$ employed in both programs enabled geometries to be optimization.

Adsorption energies were determined by optimizing the adsorbate geometry on a model $\mathrm{Cu}$ cluster of the $\mathrm{Cu}(111)$ surface ( $\mathrm{Cu}-\mathrm{Cu}$ bond length of $2.556 \AA$ ) and computing the energy change via eq 6

$$
\Delta E_{\mathrm{ADS}}=E_{\mathrm{Cu} \text { cluster-adsorbate }}-E_{\mathrm{Cu} \text { cluster }}-E_{\text {adsorbate(g) }}
$$

where $E_{\mathrm{Cu}}$ cluster-adsorbate is the energy of the adsorbate-Cu cluster complex and $E_{\mathrm{Cu}}$ cluster and $E_{\text {adsorbate(g) }}$ are the energies for the free $\mathrm{Cu}$ cluster and the gas phase adsorbate, respectively. All adsorption energies reported herein were computed from ADF calculations, whereby the adsorption energy is determined as the energy difference of the overall complex minus its respective fragments via the Ziegler transition state method. ${ }^{29}$

The $\mathrm{Cu}(8,3)$ cluster used in this work, $I$, was chosen to mimic the essential electronic features of the $\mathrm{Cu}(111)$ surface while maintaining reasonable CPU expenditures. The nomenclature $(8,3)$ refers to the arrangement of the atoms in this model; there are eight copper atoms in the surface and three atoms in the layer beneath. We have shown the effects of computed adsorption energies on cluster size and configuration for ammonia adsorption elsewhere. ${ }^{16}$ Figure 1 depicts experimental adsorption energies for atomic hydrogen and oxygen, $\mathrm{NH}_{3}$ and $\mathrm{H}_{2} \mathrm{O}$ on $\mathrm{Cu}(111)$ versus computed adsorption energies over the $\mathrm{Cu}(8,3)$ cluster. While the absolute values are slightly off $( \pm 30 \mathrm{~kJ} / \mathrm{mol})$, the deviation appears to be systematic which indicates that the relative trends are quite good. While larger clusters gave slightly more accurate adsorption energies, ${ }^{16}$ they also required considerably

(19) Baerends, E. J.; Elis, D. E.; Ros, P. Chem. Phys. 1973, 2, 41.

(20) Baerends, E. J.; Ros, P. Int. J. Quantum Chem. Symp. 1978, 12,169

(21) Boerrigter, P. M.; te Velde, G.; Baerends, E. J. Int.J.Quantum Chem. $1988,33,87$.

(22) Andzelm, J.; Wimmer, E. J. Chem. Phys. 1992, 96 (2), 1280-1303.

(23) Vosko, S. H.; Wilk, L.; Nusair, M. Can. J. Phys. 1980, 58, 1200.

(24) Becke, A. D. Phys. Rev. A 1988, 38, 3098.

(25) Becke, A. ACS Symp. Series 1989, 394, 165

(26) Perdew, J. P. Phys. Rev. B 1986, 33, 8822.

(27) Andzelm, J.; Radzio, E.; Salahub, D. R. J. Comput. Chem. 1985, 6 (6), 520-532

(28) Versluis, L.; Ziegler, T. J. Chem. Phys. 1988, 88, 322. 


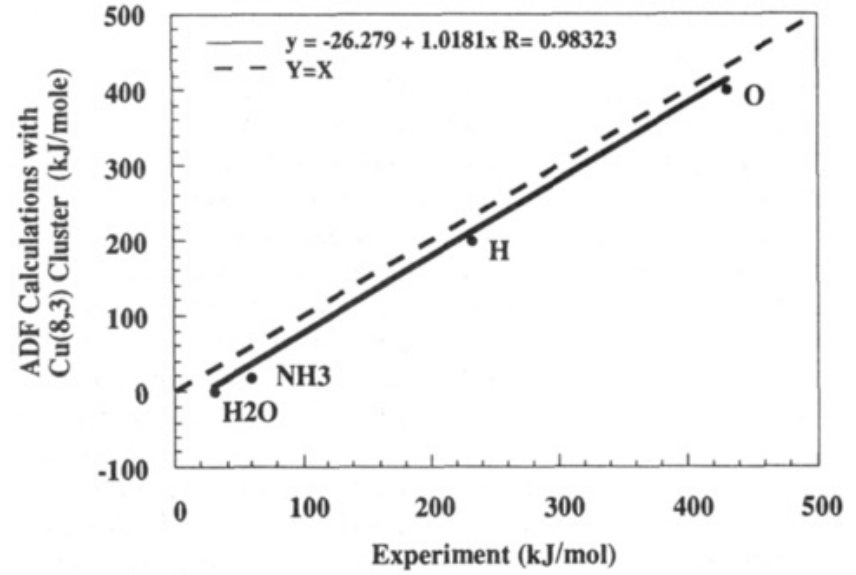

Figure 1. Comparison ADF-predicted adsorption energies for the $\mathrm{Cu}$ $(8,3)$ model cluster and experimental adsorption values on the $\mathrm{Cu}(111)$ surface. The experimental values for $\mathrm{NH}_{3}, \mathrm{H}_{2} \mathrm{O}, \mathrm{H}$, and $\mathrm{O}$ were taken from refs 44 and 45,46 and 47,31 and 31, respectively.

greater CPU times, which when coupled with demanding geometry optimization becomes computationally prohibitive.

Activation barriers were computed by choosing an appropriate reaction coordinate and optimizing the geometry of the adsorbates on the cluster at fixed points along the coordinate. All relevant

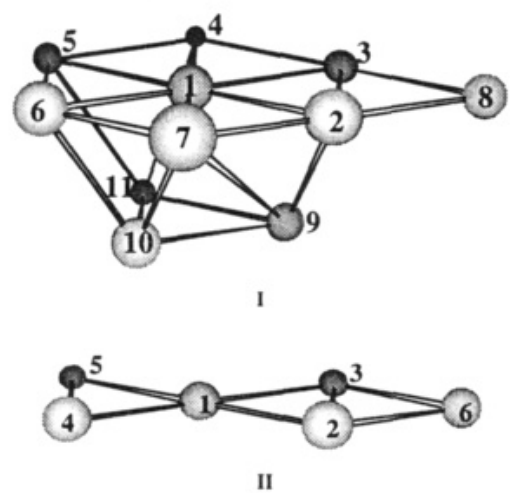

calculations were performed using the $\mathrm{Cu}(8,3)$ cluster. A minimal $\mathrm{Cu}(6)$ surface cluster (II), however, was used as an initial scoping tool. Calculations based on the $\mathrm{Cu}(6)$ cluster allowed us to judiciously choose which geometry optimizations and reaction coordinate calculations to perform on the larger $\mathrm{Cu}(8,3)$ cluster. The central surface copper in the $\mathrm{Cu}(6)$ cluster is coordinatively unsaturated and as a result overestimates the nitrogen atom binding to this site. This subsequently leads to the prediction of a much weaker nitrogen-hydrogen bond. Thus, the $\mathrm{Cu}(6)$ cluster provides a significant lower bound on activation energies for hydrogen abstraction.

\section{Results}

The results described here are divided into four sections (1) adsorption energies, (2) lateral interactions, (3) overall catalytic energy cycles and (4) activation barriers for the four mechanistic paths outlined in eqs 1-4. A substantial portion of item 1, formation and adsorption energies, was described in some of our early work. ${ }^{16-18} \mathrm{We}$, therefore, only present a short review on the important features and concentrate more heavily on items 2 and 3.

I. Adsorption Energies. The computed adsorption energies for the relevant adatoms, radical fragments, and molecular adsorbates on the $\mathrm{Cu}(8,3)$ cluster are summarized in Table 1. The energetics as well as the sites and optimized $\mathrm{Cu}$-adsorbate bond distances are reported. Ziegler ${ }^{30}$ has recently reported that

(29) Ziegler, T.; Rauk, A. Theor. Chim. Acta 1977, 46, 1.
Table 1. ADF Computed Adsorption Energies for Molecules, Radicals, and Atoms on the Model $\mathrm{Cu}(8,3)$ Cluster

\begin{tabular}{|c|c|c|c|c|}
\hline adsorbate & site & $\begin{array}{l}\text { atoms } \\
\text { defining } \\
\text { site }\end{array}$ & $\begin{array}{c}\text { distance } \\
\text { to nearest } \\
\text { Cu atom }(\AA)\end{array}$ & $\begin{array}{c}\text { adsorption } \\
\text { energy } \\
(\mathrm{kJ} / \mathrm{mol})\end{array}$ \\
\hline \multicolumn{5}{|c|}{ Molecules } \\
\hline $\mathrm{NH}_{3}$ on $\mathrm{Cu}(8,3)$ & 1 -fold & 1 & 2.41 & -16 \\
\hline \multirow[t]{4}{*}{$\mathrm{O}_{2}$ on $\mathrm{Cu}(8,3)$} & \|sym 1-fold & 1 & & +2 \\
\hline & Isym 3-fold & $2-3-8$ & 2.97 & -17 \\
\hline & $\perp 3$-fold & $2-3-8$ & 2.23 & -10 \\
\hline & $\perp 3$-fold & $1-2-3$ & 2.23 & -3 \\
\hline $\mathrm{H}_{2} \mathrm{O}$ on $\mathrm{Cu}(8,3)$ & 1 -fold & 1 & 2.7 & +1 \\
\hline $\mathrm{NO}$ on $\mathrm{Cu}(8,3)$ & 3-fold & $2-3-8$ & 2.18 & -83 \\
\hline \multicolumn{5}{|c|}{ Intermediates } \\
\hline \multirow[t]{3}{*}{$\mathrm{NH}_{2}$ on $\mathrm{Cu}(8,3)$} & 1 -fold & 1 & 1.99 & -121 \\
\hline & 2 -fold & $2-3$ & 2.14 & -178 \\
\hline & 3-fold & $1-2-3$ & 2.25 & -164 \\
\hline \multirow[t]{2}{*}{$\mathrm{NH}$ on $\mathrm{Cu}(8,3)$} & 1 -fold & 1 & 1.26 & -210 \\
\hline & 3-fold & $1-5-6$ & 1.84 & -258 \\
\hline \multirow[t]{3}{*}{$\mathrm{OH}$ on $\mathrm{Cu}(8,3)$} & 1 -fold & 1 & 1.95 & -181 \\
\hline & 2-fold & $2-3$ & 2.08 & -245 \\
\hline & 3-fold & $2-3-8$ & 2.13 & -252 \\
\hline \multirow[t]{2}{*}{$\mathrm{OOH}$ on $\mathrm{Cu}(8,3)$} & 3-fold & $2-3-8$ & 2.14 & -105 \\
\hline & & datoms & & \\
\hline $\mathrm{N}$ on $\mathrm{Cu}(8,3)$ & 3-fold & $1-5-6$ & 1.90 & -339 \\
\hline $\mathrm{O}$ on $\mathrm{Cu}(8,3)$ & 3-fold & $2-3-8$ & 1.91 & -401 \\
\hline \multirow[t]{4}{*}{$\mathrm{H}$ on $\mathrm{Cu}(8,3)$} & 1 -fold & 1 & 1.57 & -133 \\
\hline & 2-fold & $2-3$ & 1.74 & -129 \\
\hline & 3-fold & $1-2-3$ & 1.79 & -160 \\
\hline & 3-fold & $1-2-3$ & 1.68 & -175 \\
\hline
\end{tabular}

density functional methods typically predict structural bond lengths to within $0.01 \AA$ and organometallic bond energies within about $20 \mathrm{~kJ} / \mathrm{mol}$. In general, and as expected, the heats of chemisorption reported in Table 1 demonstrate the relative ordering:

molecular adsorption < radical fragment adsorption $<$ adatoms

Molecular adsorbates have a weak electrostatic surface interaction and tend to prefer onefold coordination sites, whereby Pauli repulsion is minimized. ${ }^{16,18}$ Adatoms and hydrogen deficient radical fragments such as $\mathrm{NH}$ and $\mathrm{OH}$, however, bind much more strongly and prefer the higher threefold coordination sites. The overlap between the free adatom $\mathrm{p}_{x}$ and $\mathrm{p}_{y}$ orbitals with the metal surface $s$ orbitals provides additional stabilization at the higher coordination sites which helps to increase the binding energy. Intermediate radical fragments, such as $\mathrm{NH}_{2}$, prefer twofold coordination. Interestingly, a number of these adsorption values correspond with values reported by Shustorovich ${ }^{31}$ based on bond order conservation calculations through a linear relationship, such as the one which was illustrated in Figure 1.

The adsorption of molecular oxygen is an important step in the overall cycle so we gave considerable attention to optimizing the binding of $\mathrm{O}_{2}$ to the surface. Both perpendicular and symmetric parallel adsorption over threefold coordination sites were found to be favorable steps and within $10 \mathrm{~kJ} / \mathrm{mol}$ of one another. In the parallel arrangement, the oxygen-oxygen bond is stretched from 1.21 to $1.43 \AA$, and each oxygen appears to take on a considerable negative charge. This geometry is very similar to the experimental results reported by Madix for $\mathrm{O}_{2}$ on $\mathrm{Ag}(110)$ where the oxygen-oxygen bond was found to bind parallel to the surface with an $\mathrm{O}-\mathrm{O}$ distance of $1.41 \AA .{ }^{32}$ The bond length follows the value reported for the gas phase $\mathrm{O}_{2}{ }^{2-}(1.41 \AA)^{33}$ which

(30) Ziegler, T. Chem. Rev. 1991, 91, 651-667.

(31) Shustorovich, E.; Bell, A. T. Surf. Sci. 1992, 268, 397-405.

(32) Outka, D. A.; Stöhr, J.; Jark, W.; Stevens, P.; Solomon, J.; Madix, R. J. Phys. Rev. B 1987, 35, 7891.

(33) Lide, D. R. Handbook of Chemistry and Physics, 71st ed.; CRC Press: 1990. 
Table 2. Computed Mulliken Charges for Atomic Oxygen, Molecular-Oxygen Bound Parallel, and Molecular Oxygen Bound Perpendicular to the $\mathrm{Cu}(8,3)$ Cluster Surface

\begin{tabular}{rccrcc}
\hline & & & $\mathrm{Cu}(8,3)-$ & $\begin{array}{c}\mathrm{Cu}(8,3)- \\
\mathrm{O}_{2} \text { parallel }\end{array}$ & $\begin{array}{c}\mathrm{Cu}(8,3)-\mathrm{O}_{2} \\
\text { perpendicular }\end{array}$ \\
\hline 1 & $\mathrm{Cu}$ & 0.1900 & 0.193 & 0.188 & -0.100 \\
2 & $\mathrm{Cu}$ & -0.066 & 0.016 & 0.005 & 0.036 \\
3 & $\mathrm{Cu}$ & 0.006 & -0.077 & -0.0003 & 0.083 \\
4 & $\mathrm{Cu}$ & -0.029 & 0.240 & 0.1481 & 0.033 \\
5 & $\mathrm{Cu}$ & -0.029 & 0.240 & 0.1481 & 0.033 \\
6 & $\mathrm{Cu}$ & 0.006 & -0.077 & -0.0003 & 0.083 \\
7 & $\mathrm{Cu}$ & -0.066 & 0.016 & 0.005 & 0.036 \\
8 & $\mathrm{Cu}$ & -0.098 & 0.235 & 0.117 & 0.061 \\
9 & $\mathrm{Cu}$ & 0.038 & -0.062 & -0.004 & -0.055 \\
10 & $\mathrm{Cu}$ & 0.023 & 0.010 & 0.006 & -0.0004 \\
11 & $\mathrm{Cu}$ & 0.023 & 0.010 & 0.006 & -0.0004 \\
11 & $\mathrm{Cu}$ & 0.023 & 0.010 & 0.006 & -0.0004 \\
12 & $\mathrm{O}$ & & -0.745 & -0.341 & -0.074 \\
13 & $\mathrm{O}$ & & & -0.277 & -0.255 \\
\hline
\end{tabular}

suggests that each oxygen takes on a considerable negative charge. The computed Mulliken charges are given in Table 2. Due to arbitrariness of the Mulliken population analysis to apportion the density in a chemical bond to its representative atoms, the results in Table 2 provide only an approximate qualitative measure of charge and charge transfer. The surface $\mathrm{O}_{2}{ }^{*}$ species picks up a significant charge $(-0.62)$ from its neighboring copper atoms $(4,5$, and 8 in Table 2$)$, which is in good agreement with the results reported by Fischer and Whitten ${ }^{34}\left(-0.76\right.$ for $\mathrm{O}_{2}$ bound tilted on $\mathrm{Cu}(001))$. This is somewhat lower than value for chemisorbed atomic oxygen $(-0.75)$. The combination of the long $\mathrm{O}-\mathrm{O}$ bond and the enhanced surface charge transfer to this bond suggests that the parallel arrangement is a likely precursor state for the $\mathrm{O}_{2}$ dissociation.

Interestingly, while both the $\mathrm{O}_{2}$ surface-species and chemisorbed atomic oxygen (Table 2) pick up significant charge from the $\mathrm{Cu}$ surface, the charge-transfer is not as high as two electrons. The value for atomic oxygen on $\mathrm{Cu}(8,3),-0.75$, is in good agreement with that reported by Illas et al., ${ }^{35}-0.96$ and -0.62 , and Mattsson et al. ${ }^{36}-0.85$, for $\mathrm{O}$ on $\mathrm{Cu}(4,1)$. Through a detailed analysis of (1) the projected $\mathrm{O}$ orbitals in the $\mathrm{Cu} 5 \mathrm{O}$ wave function, (2) the dipole moment curves for $\mathrm{O}$ and various point charges interactions with $\mathrm{Cu} 5$ cluster, and (3) the participation of the $\mathrm{Cu}$ $3 \mathrm{~d}$ orbitals in the $\mathrm{Cu}-\mathrm{O}$ bond, Illas and $\mathrm{Bagus}^{36 \mathrm{~b}}$ were able to extend approximate Mulliken results to find a better estimate of the charge on the oxygen, -1.5 electrons. The good agreement between the Mulliken charges reported here and those determined by Illas and Bagus suggest that the actual charge on the oxygen on the $\mathrm{Cu}(8,3)$ cluster is closer to -1.5 . This also agrees with the experimental results of Clendening et al. ${ }^{37}$ who find small increases in the work function induced by oxygen and hence a charge transfer from the metal to the oxygen less than two electrons.

For $\mathrm{O}_{2}$ adsorbed perpendicular to the surface, the optimized oxygen-oxygen distance (1.30 $\AA$ ) was found to be significantly shorter than that for $\mathrm{O}_{2}$-parallel case. The $1.30 \AA$ distance is close to the reported $1.36 \AA$ for $\mathrm{O}_{2}{ }^{-}(\mathrm{g})$. In addition, there is also a decrease in the overall charge transfer, -0.33 on $\mathrm{O}_{2}$. While the parallel mode of $\mathrm{O}_{2}$ adsorption is slightly favored on the clean $\mathrm{Cu}$ surface, the perpendicular mode, as we shall see, becomes favored in the presence of coadsorbed or preadsorbed ammonia species due to a reduction in the repulsive interactions.

The adsorption values reported in Table 1 were all determined using the same 11 atom asymmetric $\mathrm{Cu}(8,3)$ cluster, as is depicted

(34) Fischer, C.; Whitten, J. L. Phys. Rev. B 1989, 40, 8, 5745.

(35) Illas, F.; Bachs, M.; Rubio, M.; Ricart, J. M. J. Chem. Phys. 1989. $1,9,5466$.

(36) (a) Mattsson, A.; Panas, I.; Siegbahn, P.; Wahlgren, U.; Ảkeby, H. Phys. Rev. B 1987, 36, 7389. (b) Bagus, P.; Illas, F. Phys. Rev. B 19, 42, 17, 10852 .

(37) Clendening, W.; Rodiguez, J. A.; Campbell, J. A.; Campbell, C. T. Surf. Sci. 1989, 216, 429.
Table 3. Lateral Interaction Energies for the Coadsorption of Different $\mathrm{NH}_{x}$ and $\mathrm{OH}_{x}$ Species on the Model $\mathrm{Cu}(8,3)$ Cluster $^{c}$

\begin{tabular}{lccc}
\hline \multicolumn{1}{c}{ species } & case I & case II & case III \\
\hline $\mathrm{NH}_{3}$ on $\mathrm{Cu}(8,3)-\mathrm{O}$ & -32 & & \\
$\mathrm{NH}_{3}$ on $\mathrm{Cu}(8,3)-\mathrm{O}_{2}$ & -17 & & \\
$\mathrm{NH}_{2}$ on $\mathrm{Cu}(8,3)-\mathrm{OH}$ & -5 & & \\
$\mathrm{NH}$ on $\mathrm{Cu}(8,3)-\mathrm{O}$ & & +178 & +25 \\
$\mathrm{~N}$ on $\mathrm{Cu}(8,3)-\mathrm{O}$ & & & +30 \\
$\mathrm{~N}$ on $\mathrm{Cu}(8,3)-\mathrm{OH}$ & & +170 & +29 \\
\hline
\end{tabular}

${ }^{a}$ Case I refers to the adsorption of $\mathrm{Al}$ at a onefold site and $\mathrm{A} 2$ at a next-nearest neighbor threefold site. In cases II and III, the adsorbates bind at neighboring threefold sites and share two and one metal atoms, respectively. Energies are reported in $\mathrm{kJ} / \mathrm{mol}$.
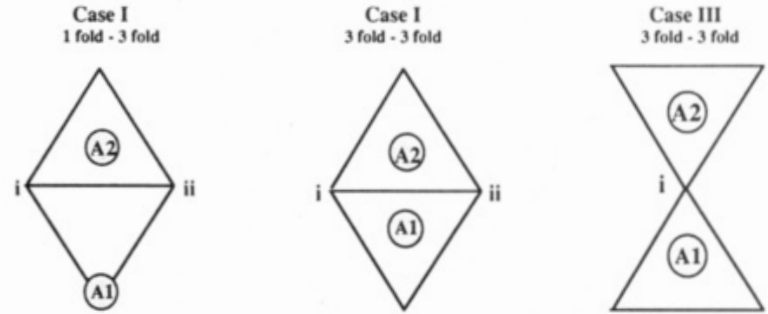

by $\mathbf{I}$ above. One can question how cluster size and cluster symmetry (or lack thereof) will affect the binding energetics on this $\mathrm{Cu}(8,3)$ cluster. The result of adding an additional $\mathrm{Cu}$ atom to the second layer to form $\mathrm{Cu}(8,4)$ changed the binding energy of both atomic nitrogen and $\mathrm{NH}_{2}$ at the center threefold site by as little as $4 \mathrm{~kJ} / \mathrm{mol}$. The local environment about a particular site was found to be much more important. Threefold sites situated directly atop of a $\mathrm{Cu}$ atom in the second layer were found to be energetically less favorable for adsorption by $40-50 \mathrm{~kJ} / \mathrm{mol}$ for both atomic nitrogen and $\mathrm{NH}_{2}$ than for those threefold sites directly above a second layer threefold hollow site.

In an effort to prove the latter question on symmetry, the binding of different adsorbates on the two symmetric copper clusters, $\mathrm{Cu}(7,3)$ III and $\mathrm{Cu}(10,3)$ IV, was examined. The adsorption energy of ammonia on $\mathrm{Cu}(7,3)$ was within $1 \mathrm{~kJ} / \mathrm{mol}$ of the value reported on $\mathrm{Cu}(8,3)$ suggesting that cluster symmetry has little effect. The adsorption energies of atomic oxygen and atomic nitrogen, on the other hand, were reduced from 401 to 362 and from 339 to $288 \mathrm{~kJ} / \mathrm{mol}$, respectively, in going from $\mathrm{Cu}(8,3)$ to $\mathrm{Cu}(10,3)$. While cluster symmetry may be responsible for the small but measurable lowering of the adsorption energies, the more likely explanation is due to changes in the cluster Fermi level.

II. Lateral Surface Interactions. Our previous results on the adsorption of ammonia on $\mathrm{Cu}(111)$ and the electronic effect of coadsorbed atomic oxygen demonstrated the significance of lateral surface interactions on measured adsorption energies. ${ }^{16,17}$ Lateral

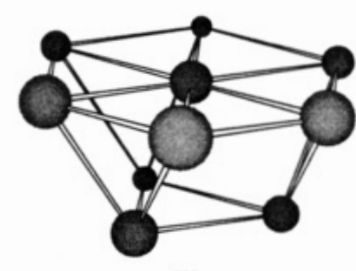

III

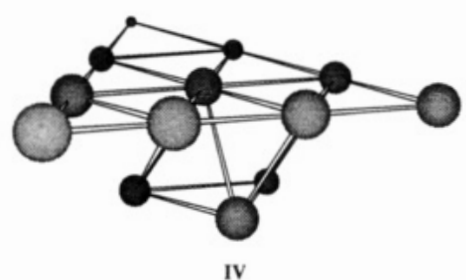

interaction energies are defined here as the enhanced or diminished adsorption energy of an adsorbate on a surface due to the presence 
Table 4. Overall Steps in the Dissociation of Ammonia to Nitrogen and Water via (A) the Atomic Oxygen Path with Sequential Hydrogen Abstraction Steps, (B) the Atomic Oxygen Path with the Simultaneous Transfer of Two Hydrogens To Form Water, (c) the Molecular Path with the Sequential Transfer of Hydrogen To Form the $\mathrm{OOH}^{*}$ Intermediate, and (D) the Molecular Path with the Simultaneous Transfer of Two Hydrogens to the Direct Formation of Water

Atomic Oxygen Paths

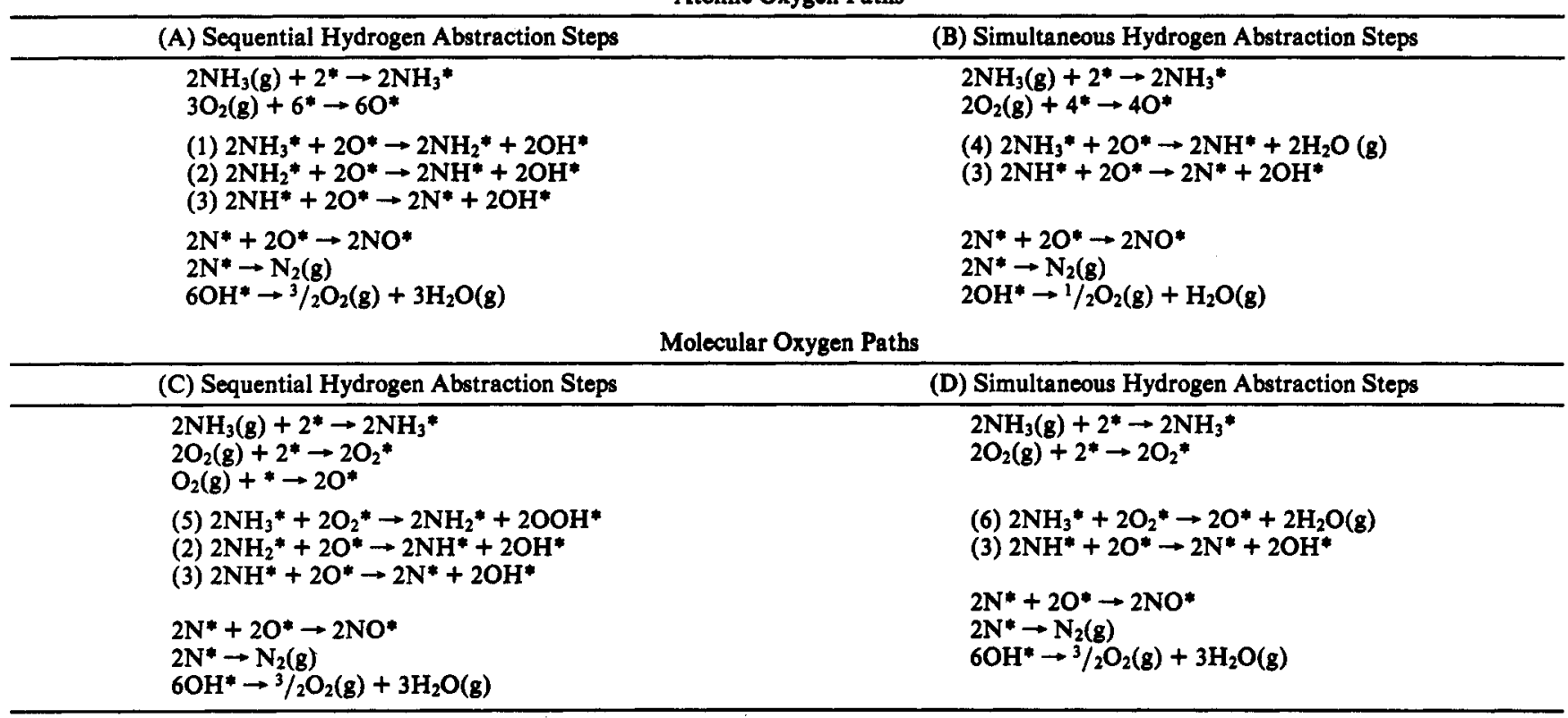

of additional surface species. The controlling enhancement or reduction should be governed predominantly by changes in the electronic surface structure, i.e., through-metal interactions rather than through-space interactions. A schematic of the adsorbate arrangement on the surface for the above example is depicted in case I of Table 3. Ammonia, which prefers the onefold adsorption site ( $\mathrm{Cu} 1$ in I or A1 from Table 3), is stabilized by $32 \mathrm{~kJ} / \mathrm{mol}$ via a through-metal attractive interaction with the neighboring threefold oxygen adsorbate (A2). A detailed electronic analysis of this type of interaction was presented elsewhere. ${ }^{17,18,38}$ The attractive interaction can be rationalized along the lines of bond order conservation ${ }^{39,40}$ and least metal atom sharing principles. ${ }^{38}$ The presence of the oxygen adsorbate weakens the bonds between nearest-neighbor ( $\mathrm{Cu} 2$ and $\mathrm{Cu} 3$ ) and next-nearest-neighbor metal atoms ( $\mathrm{Cu} 1-\mathrm{Cu} 4-\mathrm{Cu} 7-\mathrm{Cu} 9)$ which subsequently strengthens the binding at next-nearest-neighbor adsorption sites, such as the atop position for ammonia $\mathrm{A} 1(\mathrm{Cu} 1)$. The adsorption of ammonia in the presence of $\mathrm{O}_{2}{ }^{*}$ and the adsorption of $\mathrm{NH}_{2}$ in the presence of $\mathrm{OH}^{*}$ are two similar examples of the enhanced binding effects for case I type adsorption. Ammonia binds $17 \mathrm{~kJ} / \mathrm{mol}$ more strongly, and $\mathrm{NH}_{2}$ binds $5 \mathrm{~kJ} / \mathrm{mol}$ more strongly in the presence of $\mathrm{O}_{2}^{*}$ and $\mathrm{OH}^{*}$, respectively.

The case II and case III adsorption schemes depicted in Table 3 present situations where both adsorbates prefer higher coordination and sit at adjacent threefold sites. In the case II situation, the adsorbates ( $\mathrm{A} 1$ and $\mathrm{A2}$ ) share two metal atoms ( $\mathrm{i}$ and ii) in forming adsorbate-metal bonds. This "sharing" considerably weakens the metal-adsorbate bonds and gives rise to a large repulsive interaction between the two adsorbates. For example, the adsorption of $\mathrm{NH}$ on the $\mathrm{Cu}(8,3)-\mathrm{O}$ cluster, where the oxygen and NH share two metal atom centers, was found to be 178 $\mathrm{kJ} / \mathrm{mol}$ less favorable than for the adsorption of $\mathrm{NH}$ on the clean

(38) van Santen, R. A. Theoretical Heterogeneous Catalysis; World Scientific Publishing Co. Pte. Ltd.: 1991; Vol. 5.

(39) Shustorovich, E. Surf. Sci. Rep. 1986, 6, 1

(40) Shustorovich, E. Adv. Catal. 1990, 37, 101.

(41) Conrad, H.; Erti, G.; Küppers, J.; Latta, E. E. Surf. Sci. 1975, s0, 296-310.

(42) Bagus, P.; Nelin, C. J.; Avouris, Ph. J. Vac. Sci. Technol. A 1987, S, 4, 701 .
$\mathrm{Cu}(8,3)$ surface. According to the principle of least metal atom sharing, ${ }^{38}$ one should expect a large repulsive interaction. The strength of the repulsive interaction, however, can be considerably reduced by moving to a scenario where the adsorbates share only a single metal atom center (i), case III. This explains the results in Table 3, where the repulsive interactions are now reduced to $25-30 \mathrm{~kJ} / \mathrm{mol}$. These values are now in line with general experimental adsorbate-adsorbate repulsive interaction energies on transition metal surfaces. In general the results suggest that only case I and case III situations are likely on the $\mathrm{Cu}(111)$ surface.

Before proceeding to the calculation of overall reaction cycles, we first discuss the model used for the relative positioning of adsorbates on the cluster. We attempt to minimize artifacts of cluster size effects and establish an appropriate model of the real surface. Ammonia which binds weakly to the cluster will be much more sensitive to location (interior vs exterior) than the strongly chemisorbed a tomic oxygen. Therefore the more realistic arrangement of $\mathrm{NH}_{3}$ and $\mathrm{O}$ adsorbates is to have ammonia sit atop the central copper site with atomic oxygen closer to the edge. The inverse situation, where $\mathrm{NH}_{3}$ is placed at an edge site and oxygen located toward the center of the cluster, will be less representative of an extended surface because of the enhanced stability of $\mathrm{NH}_{3}$ at the unsaturated edge site. Here we analyze the analogous situation of $\mathrm{NH}_{2}$ and $\mathrm{O}$ on $\mathrm{Cu}(8,3)$. The binding energy was $140 \mathrm{~kJ} / \mathrm{mol}$ stronger for the case where $\mathrm{NH}_{2}$ was placed at an edge twofold site (with oxygen positioned in the center of the cluster) than the case in which $\mathrm{NH}_{2}$ was bound at a central edge site (with oxygen situated at a exterior hollow site). This increased binding energy (for $\mathrm{NH}_{2}$ at the edge of the cluster) is directly due to the excessive stabilization of $\mathrm{NH}_{2}$ at unsaturated metal sites. The more likely model of the extended surface is therefore the one in which atomic oxygen binds at the exterior with $\mathrm{NH}_{3}$ and $\mathrm{NH}_{2}$ occupying more central adsorption sites.

III. Overall Catalytic Cycles. The adsorption energies, gas phase formation energies, and lateral interaction energies provided the basis for computing reaction enthalpies for elementary adsorption, surface reaction, and desorption steps. Overall catalytic cycles were fashioned from these steps and are delineated 
A)

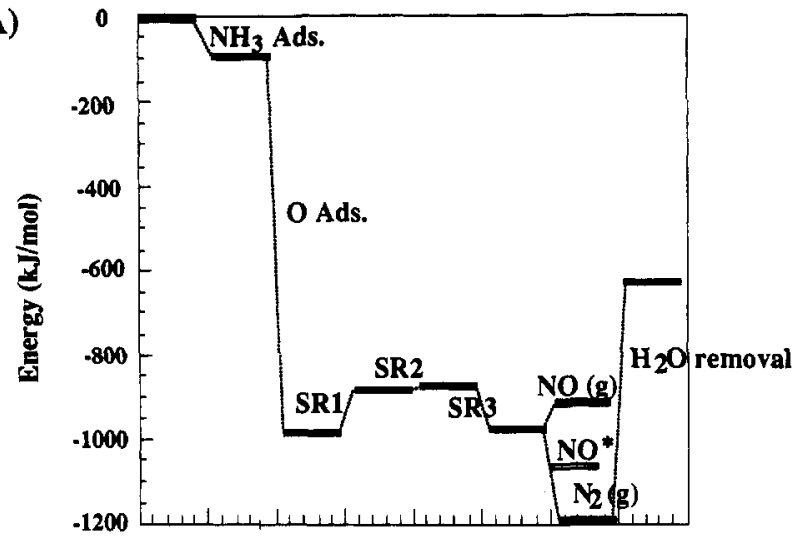

B)

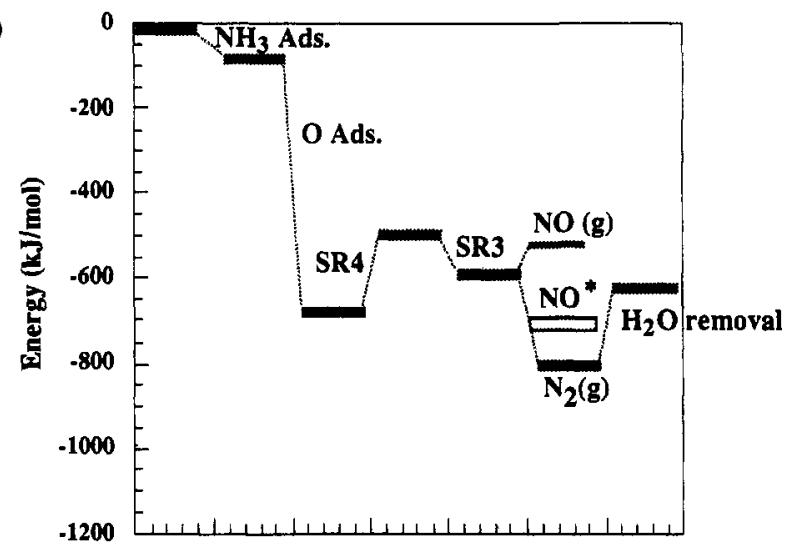

Figure 2. The overall energetics for the catalytic reaction cycle $2 \mathrm{NH}_{3}(\mathrm{~g})$ $+\mathrm{O}_{2}(\mathrm{~g}) \rightarrow \mathrm{N}_{2}(\mathrm{~g})+\mathrm{H}_{2} \mathrm{O}(\mathrm{g})$ for the mechanisms controlled by chemisotbed atomic oxygen. The two cycles shown follow two different reaction paths: (a) sequential hydrogen transfer steps to form $\mathrm{NH}_{2}{ }^{*}, \mathrm{NH}^{*}, \mathrm{~N}^{*}$, and $\mathrm{OH}^{*}$ and (b) simultaneous transfer of two hydrogens to form gaseous water and $\mathrm{NH}^{*}$ directly. This is followed by a final $\mathrm{H}$-abstraction to form $\mathrm{N}^{*}$. The first two steps in both cycles refer to the adsorprtion of $\mathrm{NH}_{3}$ and atomic oxygen. The intermediate steps SR1-SR4 are the hydrogen surface reaction steps depicted in Table 4. The final terms, $\mathbf{N}_{2}$ (g), $\mathrm{NO}^{*}, \mathrm{NO}(\mathrm{g})$, and $\mathrm{H}_{2} \mathrm{O}$ removal, refer to recombinative desorption of nitrogen adatoms to $\mathrm{N}_{2}(\mathrm{~g})$, surface reaction of $\mathrm{N}^{*}$ and $\mathrm{O}^{*}$ to form $\mathrm{NO}^{*}$, recombinative desorption of NO, and recombination of surface hydroxyl groups to form $\mathrm{H}_{2} \mathrm{O}(\mathrm{g})$, steps, respectively.

in terms of the controlling mechanistic paths defined in eqs 1-4 above. Each of these are described here in turn.

Atomic Oxygen Controlled. Two mechanistic paths exist for the cycles controlled by atomic oxygen. In the first, atomic oxygen abstracts a single hydrogen from neighboring ammonia to form surface amide and hydroxyl groups (eq 1). In the second, two of the ammonia hydrogens are simultaneously transferred from the adsorbed ammonia to the surface oxygen to yield gaseous water directly and a surface imide (eq 2). The elementary adsorption, surface reaction, and desorption steps required for the two overall cycles which follow these two different paths are outlined in Table 4A,B. The four different surface reactions are numbered in order. The corresponding reaction enthalpies for each of these steps are assembled into the overall potential energy profile for each of the two cycles, and the results are shown in Figure 2A,B.

By way of example, the adsorbate-cluster structure for each of the basic steps for the first scheme from Figure $2 \mathrm{a}$ are depicted along with corresponding stoichiometric coefficients in the cycle presented in Figure 3. In the first step, ammonia is adsorbed on the surface in the presence of oxygen at $-48 \mathrm{~kJ} / \mathrm{mol}$. The negative sign simply indicates that the step is exothermic. Additional oxygen, which is required for the overall cycle, is dissociatively adsorbed leading to a strongly bound chemisorbed atomic oxygen
$(-148 \mathrm{~kJ} / \mathrm{mol})$. The high exothermicity of this step indicates that any ad-oxygen that is formed on the surface will be very difficult to remove and thus acts to poison active surface sites. The initial ammonia dissociation step, SR1, was found to be 128 $\mathrm{kJ} / \mathrm{mol}$ more likely in the presence of oxygen than on the clean $\mathrm{Cu}(111)$ surface; however, at $+48 \mathrm{~kJ} / \mathrm{mol}$ some form of thermal energy is still required for this endothermic step. Subsequent dissociation steps, SR2 (+6 kJ/mol) and SR3 $(-48 \mathrm{~kJ} / \mathrm{mol})$, to form $\mathrm{NH}^{*}$ and $\mathrm{N}^{*}$ help to drive the energetics of the overall cycle. Thermodynamics indicate that the final nitrogen surface species favor recombination with additional $\mathrm{N}^{*}$ and desorption as $\mathrm{N}_{2}(-214 \mathrm{~kJ} / \mathrm{mol})$ over recombination with surface oxygen and desorption as $\mathrm{NO}(+46 \mathrm{~kJ} / \mathrm{mol})$. However under steady state reaction conditions, chemisorbed oxygen, which is strongly bound to the surface, will be the most abundant surface intermediate (MARI). The number of $\mathrm{N}-\mathrm{O}$ collisions will, therefore, be far greater than the number of $\mathrm{N}-\mathrm{N}$ collisions, thus implying that $\mathrm{NO}$ formation will dominate over $\mathrm{N}_{2}$ formation. Lastly, the recombination of surface hydroxyl groups to form water and chemisorbed atomic oxygen was found to be highly endothermic and is speculated as a plausible rate controlling step. The overall reaction energy for the complete catalytic cycle was computed to be $-625 \mathrm{~kJ} / \mathrm{mol}$ which is in very good agreement with the estimate of $-611 \mathrm{~kJ} / \mathrm{mol}$ from thermochemical data.

Figure 2 (part B) represents the overall potential energy diagram for the atomic oxygen mediated path in which two hydrogens are simultaneously transferred in the surface dissociation step and water is formed directly. This cycle is identical to that in Figure 2A with two exceptions: (1) less atomic oxygen is required to carry out the overall reaction and (2) the number of surface reactions is reduced from two to three due to the simultaneous transfer of two hydrogens in the initial dissociation step. The most striking feature of the cycle is the considerable energy required to dissociate the two hydrogens from ammonia. At $+92 \mathrm{~kJ} / \mathrm{mol}$, this step is now $+44 \mathrm{~kJ} / \mathrm{mol}$ more endothermic than that for the abstraction of a single hydrogen (Figure $2 \mathrm{~A}$ ).

Molecular Oxygen Controlled. The overall cycles for the molecular paths, eq 3 and 4, are reported in Table 4B and 3, and their corresponding potential energy profiles depicted in Figure 4. The path mediated by a single hydrogen transfer to form the $\mathrm{OOH}^{*}$ intermediate is shown in part a. In this scheme, ammonia and molecular oxygen are coadsorbed and react to form $\mathrm{OOH}^{*}$ and $\mathrm{NH}_{2}{ }^{*}$. A series of ammonia adsorption calculations at various $\mathrm{O}-\mathrm{O}$ surface angles indicated that the coadsorbed molecular oxygen prefers to sit perpendicular to the surface. This angle decreases somewhat as the hydrogen abstraction reaction proceeds to help shorten the distance that the hydrogen must travel. Subsequent dissociation steps lead to $\mathrm{O}^{*}, \mathrm{OH}^{*}$, and $\mathrm{NH}^{*}$ products. To complete the series of abstraction steps, $1 \mathrm{~mol}$ of dissociated $\mathrm{O}_{2}$ was required for the final step: $\mathrm{NH}^{*}+\mathrm{O}^{*} \rightarrow \mathrm{N}^{*}$ $+\mathrm{OH}^{*}$. The initial surface dissociation step for this scheme, SR5, is now exothermic and appears more likely than the considerable endothermic steps reported for dissociation on the clean $\mathrm{Cu}(111)$ surface and the atomic-oxygen-assisted dissociation. The desorption steps are the same as those reported in Table 4A and Figure 2A.

The final path analyzed, eq 4, was that for molecular-mediated oxygen dissociation and the simultaneous abstraction of two hydrogens to form gaseous water. The steps required for this scheme are outlined in Table 4D and depicted in Figure 4B. The overall potential energy profile is the most appeasing of all those studied. The cycle moves to lower energies at each subsequent elementary step until the final endothermic recombinative desorption steps. In addition, this path completely eliminates the highly exothermic oxygen dissociation step which leads to strong chemisorbed atomic oxygen that poison active surface sites. 
2
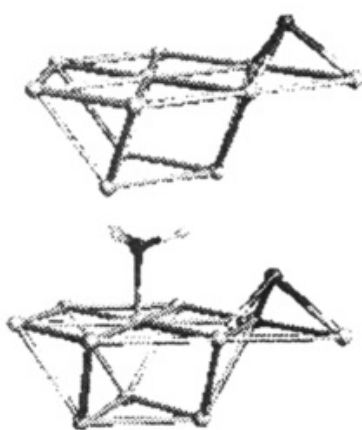

2

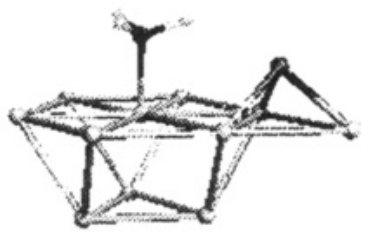

2

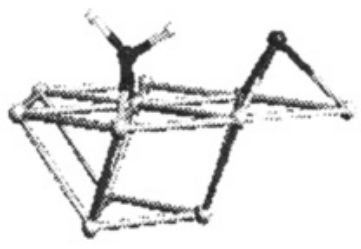

2

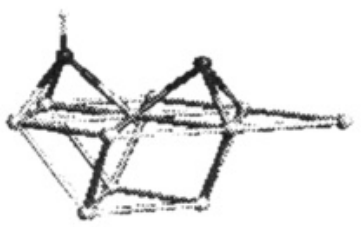

2

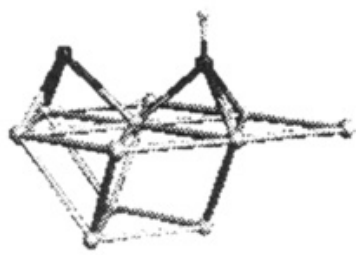

6

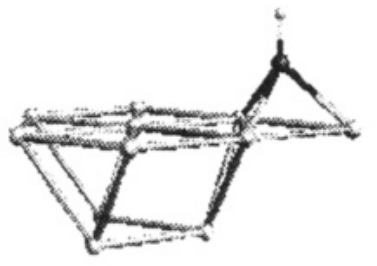

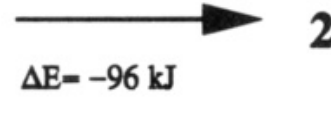

2
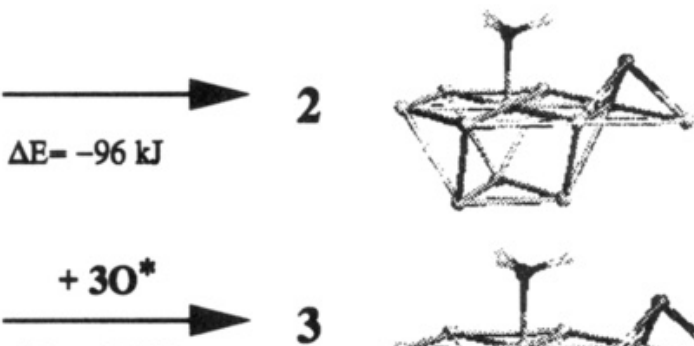

3
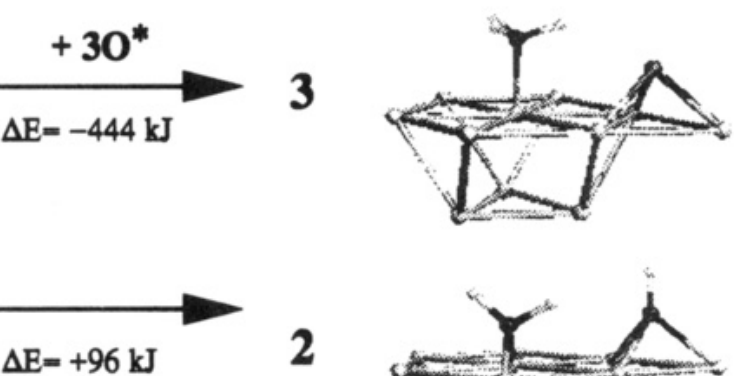

2

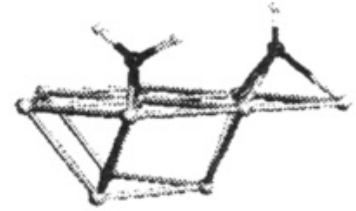

2

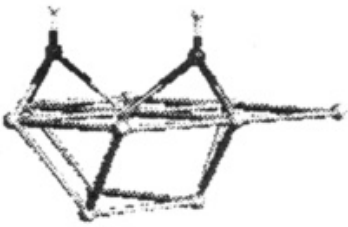

2
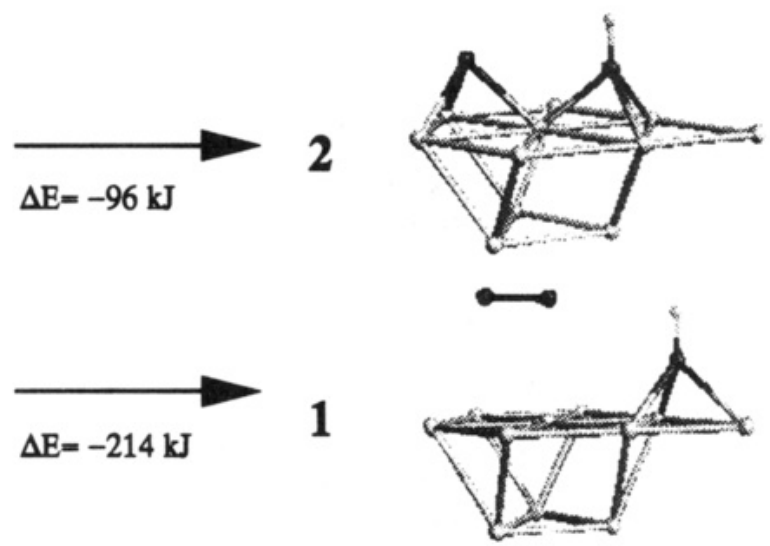

1
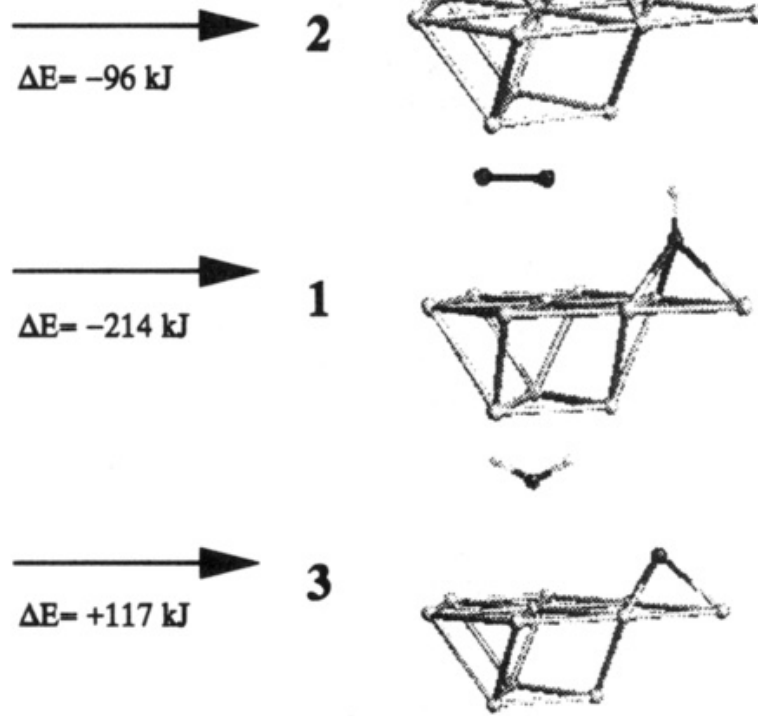

\section{Overall energy change $=-625 \mathrm{~kJ} / \mathrm{mol}$ Thermochemical estimate $=-611 \mathrm{~kJ} / \mathrm{mol}$}

Figure 3. Schematic structural representation of the overall catalytic ammonia dissociation cycle for the reaction which is controlled by atomic oxygen and follows by sequential hydrogen abstraction steps. The numbers adjacent to each cluster are the stoichiometric coefficents. The overall energies for each step are indicated in terms of kJ. Oxygen is initially present on the surface. The 3 mol of oxygen added in step 2 are required to carry out the abstraction steps.

The initial surface dissociation step

$$
\mathrm{NH}_{3}(\mathrm{a})+\mathrm{O}_{2}(\mathrm{a}) \rightarrow \mathrm{NH}(\mathrm{a})+\mathrm{O}(\mathrm{a})+\mathrm{H}_{2} \mathrm{O}(\mathrm{g})
$$

is now thermodynamically quite favorable at $-184 \mathrm{~kJ} / \mathrm{mol}$.

Activation Energies and Reaction Mechanism. In general, the overall reaction energies for each step suggest that recombinative hydroxyl removal as water and the initial hydrogen abstraction step are the most likely candidates for rate-controlling. While the former process is the more endothermic, entropy is an important factor. At higher temperatures, recombinative desorption is considerably enhanced due to the entropic contributions, and the surface reaction steps become more predominant in controlling the mechanism. We, therefore, analyzed the activation barriers for each of the initial surface reaction steps shown in eqs $1-4$.

Atomic Oxygen. We reported the activation barrier for ammonia dissociation in the presence of atomic oxygen in a previous communication. ${ }^{18}$ The dissociation was modeled as a two-step process: $\mathrm{N}-\mathrm{H}$ bond activation with the nitrogen fixed 
A)

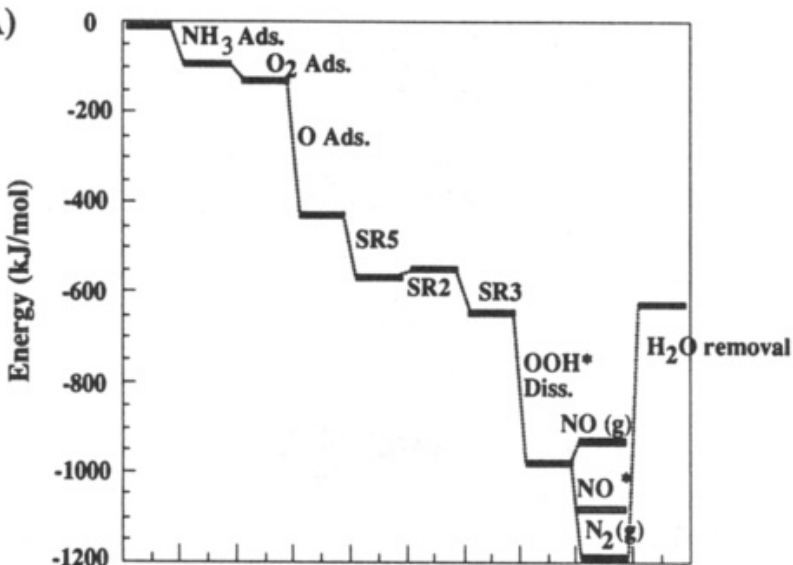

B)

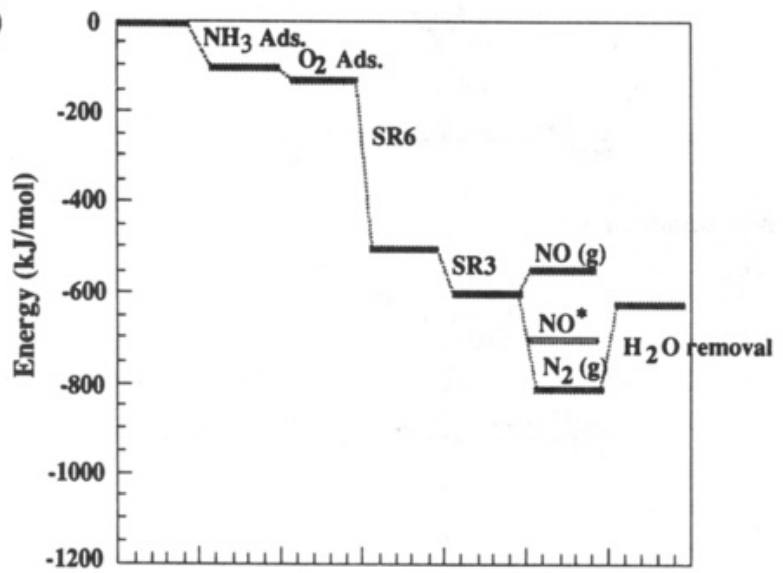

Figure 4. The overall energetics for the catalytic reaction cycle $2 \mathrm{NH}_{3}(\mathrm{~g})$ $+\mathrm{O}_{2}(\mathrm{~g}) \rightarrow \mathrm{N}_{2}(\mathrm{~g})+\mathrm{H}_{2} \mathrm{O}(\mathrm{g})$ for the mechanisms controlled by molecular oxygen. The two cycles shown follow two different reaction paths: (a) sequential hydrogen transfer steps to form $\mathrm{NH}_{2}{ }^{*}, \mathrm{NH}^{*}, \mathrm{~N}^{*}$, and $\mathrm{OOH}^{*}$ and (b) simultaneous transfer of two hydrogens to form gaseous water and $\mathrm{NH}^{*}$ directly. This is followed by a final $\mathrm{H}$-abstraction to form $\mathrm{N}^{*}$. The first two steps in both cycles refer to the adsorption of $\mathrm{NH}_{3}$ and molecular oxygen. The intermediate steps SR2-SR6 are the hydrogen surface reaction steps depicted in Table 4. The final terms, $\mathrm{N}_{2}(\mathrm{~g}), \mathrm{NO}^{*}$, $\mathrm{NO}(\mathrm{g}), \mathrm{OOH}^{*}$ Diss., and $\mathrm{H}_{2} \mathrm{O}$ removal, refer to recombinative desorption of nitrogen adatoms to $\mathrm{N}_{2}(\mathrm{~g})$, surface reaction of $\mathrm{N}^{*}$ and $\mathrm{O}^{*}$ to form $\mathrm{NO}^{*}$, recombinative desorption of $\mathrm{NO}$, dissociation of surface $\mathrm{OOH}^{*}$ to form $\mathrm{O}^{*}$ and $\mathrm{OH}^{*}$, and recombination of surface hydroxyl groups to form $\mathrm{H}_{2} \mathrm{O}(\mathrm{g})$, steps, respectively.

at the onefold site and surface diffusion of the $\mathrm{NH}_{2}{ }^{*}$ product to the stable twofold binding site. The initial N-H activation step was found to be controlling with an activation barrier of +132 $\mathrm{kJ} / \mathrm{mol}$. The surface reactants, transition complex, and surface products for this reaction along with the associated activation energy and overall reaction energy are depicted in Figure 5.

The detailed reaction coordinate for the simultaneous activation of two NH bonds by atomic oxygen was analyzed here on the $\mathrm{Cu}$ (6) cluster. The $\mathrm{N}-\mathrm{H}$ bond stretch was chosen as the reaction coordinate. All other adsorbate-surface variables were optimized at each position along this coordinate. The results are shown in Figure 6. As the two $\mathrm{N}-\mathrm{H}$ bonds stretch, the resulting $\mathrm{NH}^{*}$ fragment rotates toward the threefold site which is adjacent to the $\mathrm{H}_{2} \mathrm{O}$ species that is being formed. This is illustrated by the decreasing $\mathrm{N}-\mathrm{H}$ surface angle along the reaction coordinate in Figure 6. All three oxygen-copper bonds elongate as gaseous water is formed. The two $\mathrm{O}-\mathrm{Cu}$ bonds closest to the nitrogenbound adsorbate, however, increase somewhat more substantially. At the N-H stretch of $1.5 \AA$, for example the oxygen-copper distances are $2.10 \AA$ for $\mathrm{O}-\mathrm{Cu} 2$ and $\mathrm{O}-\mathrm{Cu} 3$ and $1.874 \AA$ for O-Cu6. This increase in the bond distance is attributed to the repulsive interaction between the oxygen which still maintains some interaction with the surface and the neighboring $\mathrm{NH}$

\section{Surface Reactants $\quad \Delta \mathbf{E}=0 \mathbf{k J} / \mathbf{m o l}$}

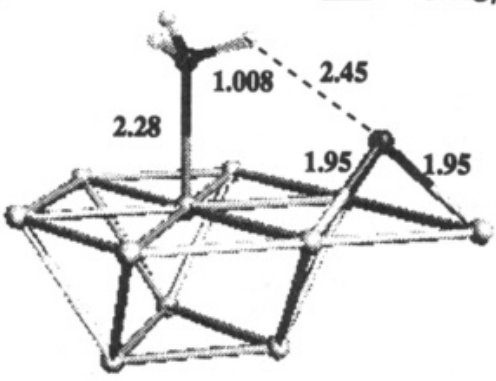

\section{Transition Complex $\Delta \mathrm{E}=132 \mathrm{~kJ} / \mathrm{mol}$}

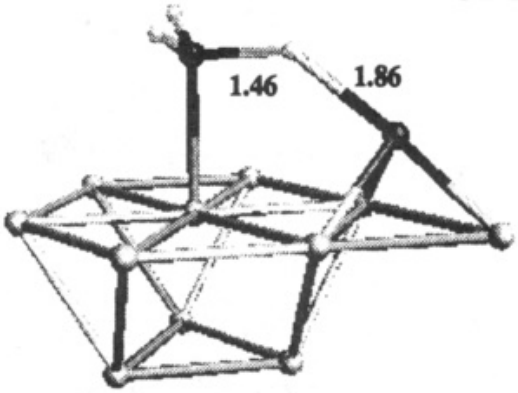

Surface Products

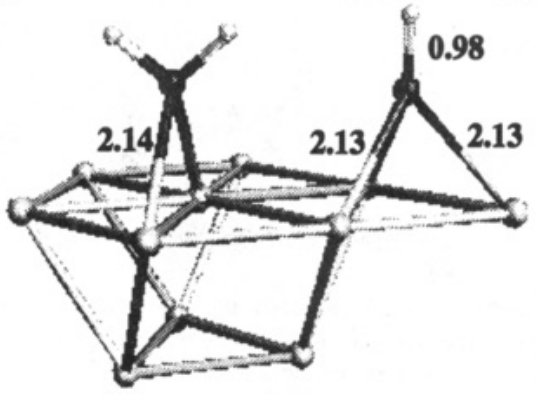

Figure 5. Summary of important structural and energetic features for path 1 dissociation of ammonia. Atomic oxygen abstracts a single hydrogen from the coadsorbed ammonia on the $\mathrm{Cu}(8,3)$ cluster. Bond lengths are reported in $\AA$.

fragment which is forming. The release of water to the gas phase essentially removes this repulsive interaction and thus allows the surface imide to be formed toward the front of the cluster. Had the water remained adsorbed, the $\mathrm{NH}^{*}$ species would have more likely moved toward the back of the cluster which is in accord with the principle of least metal atom sharing. The transition state occurs as the $\mathrm{N}-\mathrm{H}$ bond is stretched $0.32 \AA$ from its original equilibrium distance $(1.028 \AA)$. This corresponds to an activation barrier of $204 \mathrm{~kJ} / \mathrm{mol}$. However, as was discussed earlier, this simple $\mathrm{Cu}(6)$ cluster underpredicts the $\mathrm{NH}$ bond strength and therefore provides only a lower bound on the energy barrier. The true activation energy is therefore $>204 \mathrm{~kJ} / \mathrm{mol}$, which makes this an unlikely reaction path.

Molecular Oxygen. The $\mathrm{N}-\mathrm{H}$ bond stretch was also chosen as the reaction coordinate for the abstraction of a single hydrogen by molecular oxygen to form $\mathrm{OOH}^{*}$. Reaction coordinate calculations were performed on both the $\mathrm{Cu}(6)$ and $\mathrm{Cu}(8,3)$ clusters, and the results are shown in Figure 7 and 8, for the two respective clusters. As discussed earlier, $\mathrm{O}_{2}$ initially prefers the near-perpendicular adsorption geometry in the presence of $\mathrm{NH}_{3}$. The $\mathrm{O}-\mathrm{O}$ surface angle decreases very slightly as the reaction proceeds to shorten the distance and hydrogen must travel to the neighboring oxygen. However, once the hydrogen begin binding with the oxygen, the $\mathrm{O}-\mathrm{O}$ surface angle returns to the perpendicular state. In general, the results in Figure 7 and 8 demonstrate 
Initial

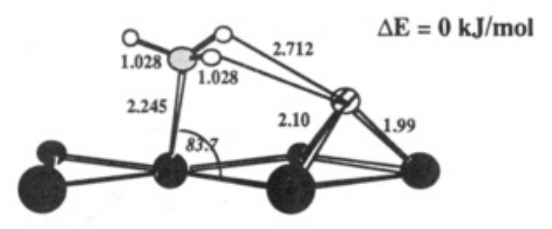

N-H Distance $1.1 \AA$

$\Delta \mathrm{E}=15 \mathrm{~kJ} / \mathrm{mol}$

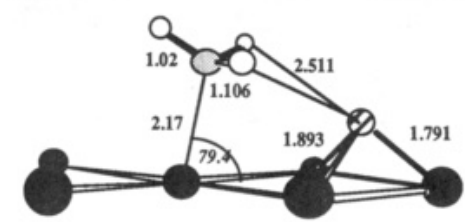

$N$-H Distance $1.25 \AA$

$\Delta \mathrm{E}=117 \mathrm{~kJ} / \mathrm{mol}$

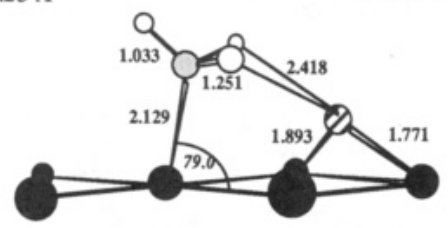

$N$-H Distance $1.35 \AA$

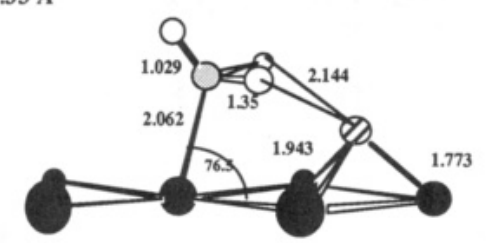

N-H Distance 1.5 A

$\Delta \mathrm{E}=183 \mathrm{~kJ} / \mathrm{mol}$

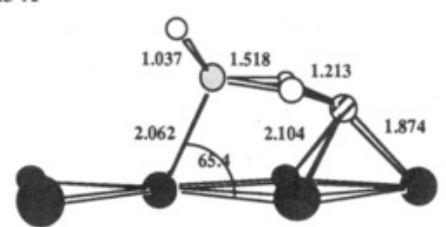

Figure 6. Reaction coordinate calculations for the path 2 dissociation of ammonia over the $\mathrm{Cu}(6)$ cluster. Atomic oxygen abstracts two hydrogens from the coadsorbed ammonia which ultimately results in $\mathrm{NH}^{*}$ and the formation of gaseous water. The $\mathrm{N}-\mathrm{H}$ stretch is taken as the reaction coordinate and $E$ refers to total electronic energies (in atomic units) at particular points along the coordinate. $\Delta E$ is the change in energy with respect to the initial adsorbed state and is reported in $\mathrm{kJ} / \mathrm{mol}$. Bond lengths are reported in $\AA$.

that as the $\mathrm{N}-\mathrm{H}$ bond is elongated the $\mathrm{Cu}-\mathrm{N}$ distance decreases, the $\mathrm{O}-\mathrm{Cu}$ distance decreases and the $\mathrm{O}-\mathrm{O}$ distance increases. This corresponds with the development of a stronger $\mathrm{Cu}-\mathrm{N}, \mathrm{O}-\mathrm{Cu}$ bonds and a weaker $\mathrm{O}-\mathrm{O}$ bond and follows along the lines of the BOC principle. The low activation energy $(+29 \mathrm{~kJ} / \mathrm{mol})$ and the shorter $\mathrm{N}-\mathrm{Cu}$ bonds on the $\mathrm{Cu}(6)$ cluster are clear evidence of the $\mathrm{Cu}(6)$ model's overprediction for $\mathrm{Cu}-\mathrm{N}$ binding and hence underprediction for $\mathrm{N}-\mathrm{H}$ bond breaking. This helps to establish the role of the $\mathrm{Cu}(6)$ for providing lower limits on $\mathrm{N}-\mathrm{H}$ dissociation barrier. The $\mathrm{Cu}(8,3)$ system yields a much more accurate representation and predicts an activation energy of $+67 \mathrm{~kJ} / \mathrm{mol}$. The results presented in Figure 8 are from DGauss calculations. The activation energy result was repeated using the ADF program and found to be within $5 \mathrm{~kJ} / \mathrm{mol}(+62 \mathrm{~kJ} / \mathrm{mol})$.

This reaction is quite late in the $\mathrm{N}-\mathrm{H}$ stretch. It is not until the surface amide diffuses to the more favorable twofold site and rotates about the surface-nitrogen bond to a more favorable bonding arrangement where the remaining $\mathrm{N}-\mathrm{H}$ bonds are perpendicular to the $\mathrm{Cu}-\mathrm{Cu}$ bond (as is shown in the final two structures in Figure 8) that the reaction energy becomes favorable $(\Delta E<0)$. From Figure 6 it is clear that the $\mathrm{NH}_{2}$ prefers the twofold site which is one copper atom removed from the binding of the $\mathrm{OOH}^{*}$ species. This arrangement is similar to that shown in case I above, whereby the through-metal interaction stabilizes
Initial

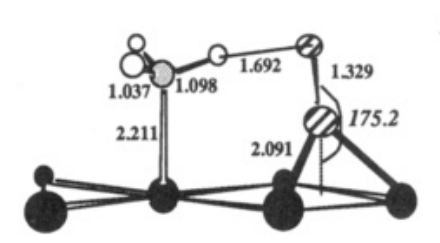

$N$-H Distance $1.4 \AA$

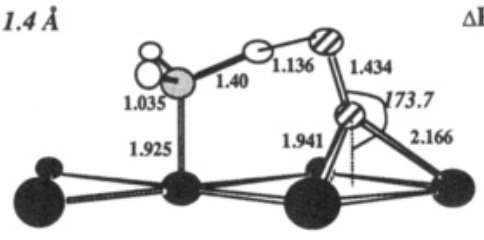

$\Delta E=21.3 \mathrm{~kJ} / \mathrm{mol}$

$N$-H Distance $1.5 \AA$

$\Delta \mathrm{E}=\mathbf{2 4} \mathrm{kJ} / \mathrm{mol}$

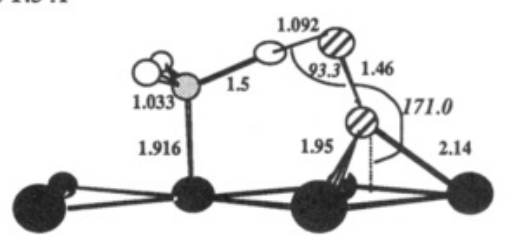

N-H Distance $1.7 \AA$

$\Delta \mathbf{E}=29 \mathrm{~kJ} / \mathrm{mol}$

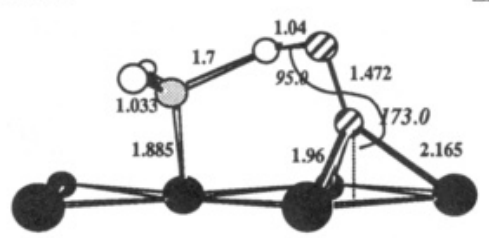

Final

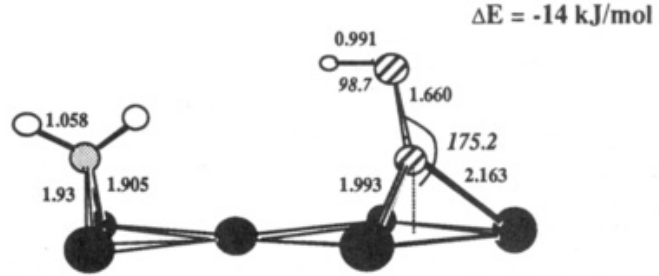

Figure 7. Reaction coordinate calculations for the path 3 dissociation of ammonia over $\mathrm{Cu}(6)$. Molecular oxygen acts to abstract a single hydrogen from the coadsorbed ammonia to form $\mathrm{NH}_{2}{ }^{*}$ and $\mathrm{OOH}^{*}$ intermediates. The $\mathrm{N}-\mathrm{H}$ stretch is taken as the reaction coordinate, and $E$ refers to total electronic energies (in atomic units) at particular points on the coordinate. $\Delta E$ is the change in energy with respect to the initial adsorbed state and is reported in $\mathrm{kJ} / \mathrm{mol}$. Bond lengths are reported in $\AA$.

the binding of both adsorbates. One last point worth noting is the difference between the three $\mathrm{Cu}-\mathrm{O}$ bond lengths. In path 2 above, where atomic oxygen abstracted two hydrogens, the water and $\mathrm{NH}^{*}$ species were in close proximity, and therefore repulsive interactions lead the $\mathrm{O}-\mathrm{Cu} 2$ and $\mathrm{O}-\mathrm{Cu} 3$ to be somewhat longer. In this path (eq 3), however, the through-metal interaction increases the binding and hence decreases the $\mathrm{O}-\mathrm{Cu} 2$ and $\mathrm{O}-\mathrm{Cu} 3$ bond lengths.

In the final mechanistic path, eq 4 , molecular oxygen acts to simultaneously abstract two hydrogens from the coadsorbed ammonia to form water directly. The $\mathrm{N}-\mathrm{H}$ bond stretch was once again chosen as the reaction coordinate. The results are depicted in Figure 9 on the $\mathrm{Cu}(6)$ cluster and suggest that the activation energy for this path is greater than $+172 \mathrm{~kJ} / \mathrm{mol}$. The activation barrier for this path is considerably higher than that for the abstraction of a single hydrogen. This is attributed to the longer initial N-H distances (1.66 vs $2.41 \AA$ for path 4$)$ and the necessity to activate two bonds rather than one. In fact, if one compares the $\mathrm{N}-\mathrm{H}$ bond length for the initial adsorbates in path $3(1.098 \AA$ on $\mathrm{Cu}(6)$ and $1.07 \AA$ on $\mathrm{Cu}(8,3))$ to those for path $4(1.021 \AA$ on $\mathrm{Cu}(6)$ and $1.03 \AA$ on $\mathrm{Cu}(8,3))$, it appears that the NH bond for path 3 is initially activated as a result of the short initial O-H distance. There is no initial activation, however, for path 4 . 

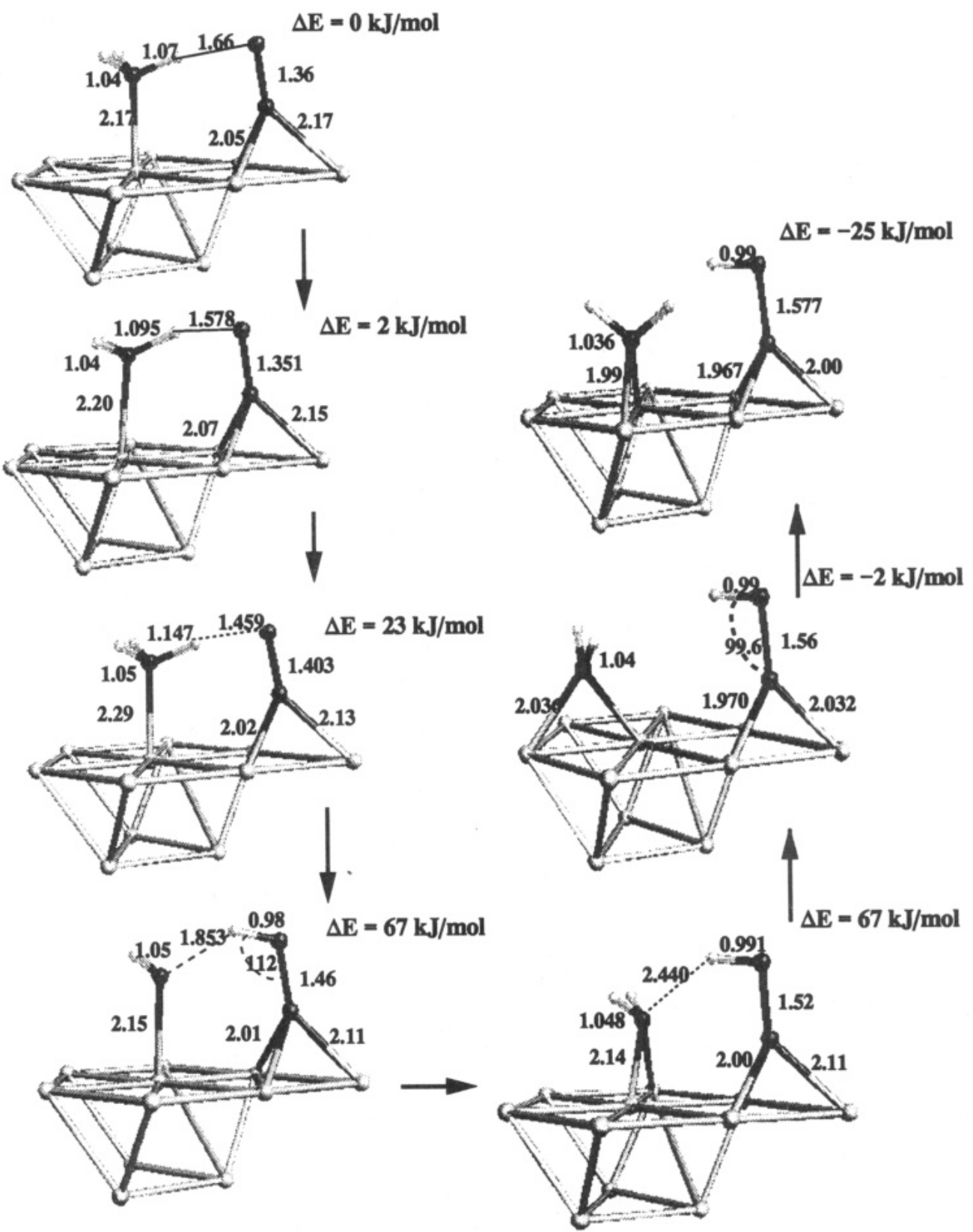

Figure 8. Reaction coordinate calculations for the path 3 dissociation of ammonia over $\mathrm{Cu}(8,3)$. Molecular oxygen abstracts a single hydrogen from the coadsorbed ammonia to form $\mathrm{NH}^{*}$ and $\mathrm{OOH}^{*}$ intermediates. The $\mathrm{N}-\mathrm{H}$ stretch is taken as the reaction coordinate. $\Delta E$ is the change in energy with respect to the initial adsorbed state and is reported in $\mathrm{kJ} / \mathrm{mol}$. Bond lengths are reported in $\AA$.

An energetically more favorable reaction coordinate for this path was found to be the stretch of the weak oxygen-oxygen bond. A summary of the reaction coordinate results for this step are provided in Figure 10. The activation energy for this path is $+134 \mathrm{~kJ} / \mathrm{mol}$, and the transition state appears to be early in the $\mathrm{N}-\mathrm{H}$ stretch $(+0.032 \AA)$ but late with respect to the $\mathrm{O}-\mathrm{O}$ stretch $(+1.02 \AA)$. As the $\mathrm{O}-\mathrm{O}$ bond is stretched, the $\mathrm{Cu}-\mathrm{O}$ bond becomes shorter, and the two hydrogens are separated from the chemisorbed ammonia to form water in the gas phase and a surface imide which sits threefold. The results from path 2 (Figure 6) demonstrated that the $\mathrm{NH}^{*}$ preferred to move forward on the cluster toward the releasing water. However, in path 4 , as is shown here in Figure 10, the surface imide actually prefers to move toward the threefold site at the back of the cluster, away from the threefold chemisorbed oxygen. Had the $\mathrm{NH}^{*}$ moved to the threefold site directly in front of it both the $\mathrm{NH}^{*}$ and $\mathrm{O}^{*}$ would share two metal atom neighbors, a case II scenario, which was found to be considerably repulsive.

Nitric Oxide Formation. While recombination of nitrogen and oxygen adatoms and desorption as NO is thermodynamically less favorable than recombinative desorption of $\mathrm{N}_{2}$, the substantially higher oxygen surface coverages make the NO path much more likely. To further investigate this we computed the detailed potential energy profile for the adsorption and dissociation of NO over the $\mathrm{Cu}(8,4)$ cluster. Figure 11 depicts the important structural results and a summary of the corresponding energetics, while Figure 12 provides a more complete potential energy profile. $\mathrm{NO}$ adsorbs molecularly at the threefold adsorption site $(\mathrm{N}-\mathrm{Cu}$ and $\mathrm{N}-\mathrm{O}$ bond distances of 2.18 and $1.15 \AA$, respectively) and releases $83 \mathrm{~kJ} / \mathrm{mol}$. This adsorption energy agrees quite well with the experimental value of $105 \mathrm{~kJ} / \mathrm{mol}$ reported by Conrad and Ertl for $\mathrm{NO}$ on Ni(111). ${ }^{41}$ Nickel is expected to be more active than copper due to vacancies in its valence electron band, and thus the adsorption energy on $\mathrm{Ni}(111)$ should be somewhat greater. The computed adsorption energy also follows the ab initio MCSCF results reported by Bagus et al. ${ }^{42}$ for NO atop $\mathrm{Cu}(1,4)$ which indicate adsorption energies of $80-100 \mathrm{~kJ} / \mathrm{mol}$.

A linear transient between the optimized NO reactant and the dissociated product state was chosen as the reaction coordinate for NO dissociation reaction. The activation barrier was 


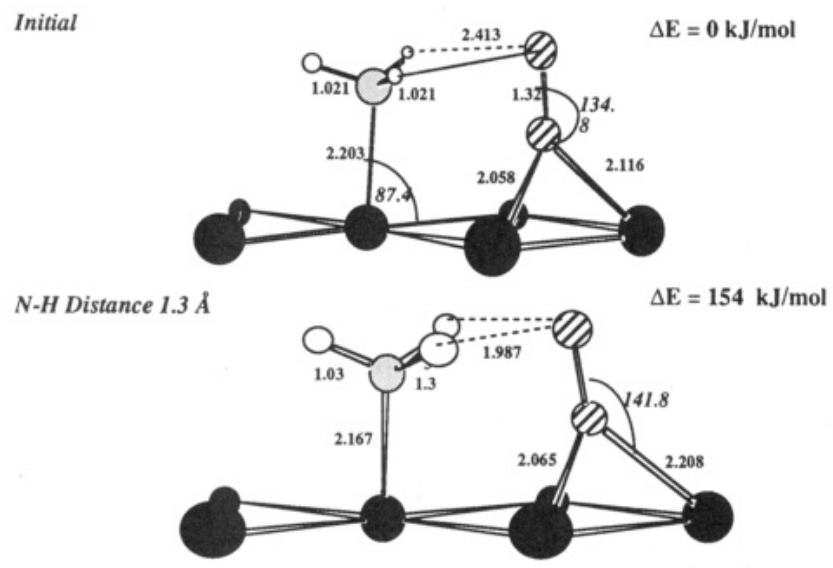

\section{N-H Distance $1.7 \AA$}

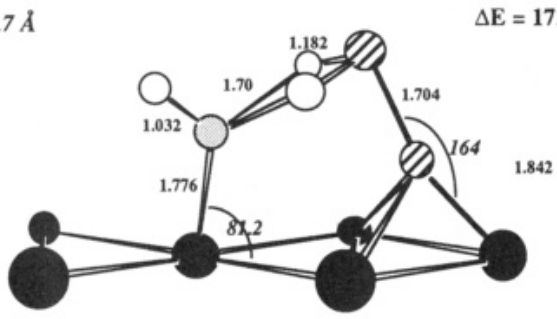

Final
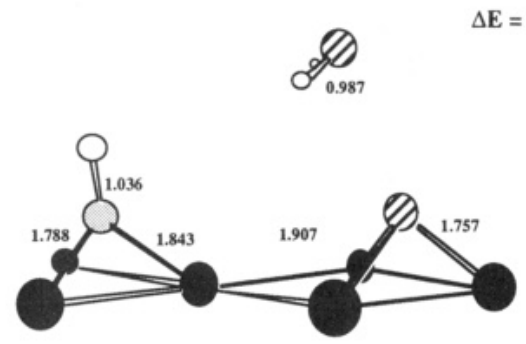

Figure 9. Reaction coordinate calculations for the path 4 dissociation of ammonia over $\mathrm{Cu}(6)$. Molecular oxygen acts to abstract a two hydrogen from the coadsorbed ammonia to form $\mathrm{NH}^{*}, \mathrm{O}^{*}$, and gaseous water. The $\mathrm{N}-\mathrm{H}$ stretch is taken as the reaction coordinate. $E$ refers to total electronic energies (in atomic units) at particular points along the coordinate, and $\Delta E(\mathrm{~kJ} / \mathrm{mol})$ is the change in energy with respect to the initial adsorbed state. Bond lengths are reported in $\AA$.

computed by optimizing $\mathrm{N}-\mathrm{O}$ surface interactions at a number of points along the reaction coordinate. The resulting barrier is $+88 \mathrm{~kJ} / \mathrm{mol}$ with respect to the gas phase (or $+51 \mathrm{~kJ} / \mathrm{mol}$ for the reverse reaction $\mathrm{N}-\mathrm{O}$ recombination). The associated transition state structure shown in Figure 11 appears to be quite late with respect to the $\mathrm{N}-\mathrm{O}$ stretch $(+1.025 \AA)$ and close in proximity to the dissociated product state. The reaction proceeds over a single metal surface atom, thus resulting in $\mathrm{N}^{*}$ and $\mathrm{O}^{*}$ products in a case III type situation. The barrier to dissociate NO over a twofold site, i.e., a case II situation, would have been much more costly in terms of energy.

At low coverages, the $\mathrm{N}^{*}$ and $\mathrm{O}^{*}$ products diffuse to apart, as is depicted in the final step of Figure 12, to remove the 30 $\mathrm{kJ} / \mathrm{mol}$ repulsive interaction. The dissociative adsorption energy to the intermediate state, where $\mathrm{N}^{*}$ and $\mathrm{O}^{*}$ share a single metal center, is $-46 \mathrm{~kJ} / \mathrm{mol}$, while that to the separated $\mathrm{N}^{*}$ and $\mathrm{O}^{*}$ products is $-76 \mathrm{~kJ} / \mathrm{mol}$. The reverse reaction of $\mathrm{N}^{*}$ and $\mathrm{O}^{*}$ recombination to molecularly bound NO is slightly exothermic. When this step is coupled with the desorption of NO from the surface, the overall recombinative desorption process becomes endothermic.

\section{Discussion}

The various reaction paths for the dissociation of ammonia studied herein are summarized in Table 5. While the $\mathrm{Cu}(111)$ surface helps to lower both the endothermicity and the activation barrier for ammonia dissociation considerably, the substantial activation barrier and reaction enthalpy indicate that little dissociation will occur over the clean $\mathrm{Cu}(111)$ surface. The presence of atomic oxygen decreases the activation barrier and the endothermicity even further. The activation energy is now low enough that moderate dissociation is likely at high temperatures and very low surface coverages. The high exothermicity which accompanies the dissociative adsorption of oxygen, however, indicates that chemisorbed oxygen will poison the surface and impede ammonia dissociation kinetics. All of these results are consistent with the experimental findings presented by Roberts and colleagues on $\mathrm{Cu}(110)^{11,12}$ and $\mathrm{Cu}(111)^{14}$ where at low coverages of preadsorbed oxygen, ammonia dissociation occurs but at a rather slow rate. At higher coverages the ammonia dissociation path shuts down, and chemisorbed oxygen overlayers poison the surface.

Of the two candidates of atomic-oxygen-assisted dissociation, we find that the sequential hydrogen dissociation path (eq 1) is more likely. In this path, the ammonia hydrogen and surface $\mathrm{O}^{*}$ are significantly closer, only one $\mathrm{N}-\mathrm{H}$ bond needs to be cleaved, and the strong $\mathrm{Cu}-\mathrm{O}$ bond does not have to be broken. The activation barrier is over $72 \mathrm{~kJ} / \mathrm{mol}$ lower in energy, and the overall reaction energy $44 \mathrm{~kJ} / \mathrm{mol}$ is more exothermic for the mechanism based on single hydrogen transfer steps over the mechanism for the simultaneous transfer of two hydrogens.

The results presented above and summarized in Table 5 clearly indicate that molecular oxygen acts as chemical precursor in the dissociation of ammonia. Both the sequential and simultaneous hydrogen abstraction paths (paths 3 and 4) are largely exothermic. Molecular oxygen is weakly bound perpendicular to the $\mathrm{Cu}$ surface with an adsorption energy of $-10 \mathrm{~kJ} / \mathrm{mol}$. Electron back donation from the surface to the $\pi^{*}$ orbital of $\mathrm{O}_{2}$ weakens the $\mathrm{O}-\mathrm{O}$ bond which is reflected by the longer $\mathrm{O}-\mathrm{O}$ distance $\left(\mathrm{O}_{2}{ }^{*}=1.36 \AA\right.$, $\left.\mathrm{O}_{2}(\mathrm{~g})=1.21 \AA\right)$. The weakly bound molecular oxygen can then readily abstract hydrogen from the coadsorbed ammonia. The initial distance between the ammonia hydrogen and the oxygen atom that is transferred to is now only $1.66 \AA$ for path 3 , whereas for the atomic oxygen abstraction the distance was $2.45 \AA$. While the overall thermodynamics favor the simultaneous hydrogen abstraction to form water directly, the activation barriers indicate that the sequential path which is $67 \mathrm{~kJ} / \mathrm{mol}$ less costly predominates. The relatively close initial $\mathrm{O}-\mathrm{H}$ distance and the need to break only one $\mathrm{NH}$ bond once again are likely explanations why path 3 is favored over path 4 . In addition, these explanations help to clarify the change in the reaction coordinate in going from path 3 (controlled by the $\mathrm{N}-\mathrm{H}$ stretch) to path 4 (controlled by $\mathrm{O}-\mathrm{O}$ stretch). In path 3 , the $\mathrm{N}-\mathrm{H}$ stretch is activated by the close proximity $\mathrm{N}-\mathrm{H}$ hydrogen and the neighboring oxygen. In path 4 , however, the oxygen-hydrogen distance is significantly longer thus reducing $\mathrm{N}-\mathrm{H}$ bond activation. $\mathrm{NH}$ bond scission is therefore much more costly than stretching of the weak $\mathrm{O}-\mathrm{O}$ bond. In the end, the energy required for the significant $\mathrm{O}-\mathrm{O}$ stretch in path 4 is greater than the energy needed to cleave the activation NH bond in path 3 .

Under the typical UHV conditions of Roberts ${ }^{11-14}$ and at low oxygen partial pressures, the apparent activation energy for $\mathrm{NH}_{3}$ dissociation is really a measure of both the intrinsic $\mathrm{NH}$ bond scission and equilibrium adsorption constants for $\mathrm{NH}_{3}$ and $\mathrm{O}_{2}$. For path 4 the apparent activation barrier is $+67 \mathrm{~kJ} / \mathrm{mol}$, whereas for the more likely path 3 the apparent activation barrier is 0 $\mathrm{kJ} / \mathrm{mol}$. Path 3 is essentially a nonactivated route for molecular oxygen dissociation of ammonia under these conditions. Molecular oxygen dissociation may be in direct competition with this path for the consumption of $\mathrm{O}_{2}$. Boostma et al., ${ }^{43}$ however, determined that the apparent activation for $\mathrm{O}_{2}$ dissociation over

(43) Habraken, F. H. P. M.; Kiefer, E. Ph.; Bootsma, G. A. Surf. Sci. 1979, 83, 45-59.

(44) Wu, K. J.; Kevan, S. D. J. Chem. Phys. 1991, 94, 7494.

(45) Chuang, T. J.; Seki, H.; Hussla, I. Surf. Sci. 1985, 158, 525.

(46) Hinch, B. J.; Dubois, L. H. J. Chem. Phys. 1992, 96, 4, 3262. 


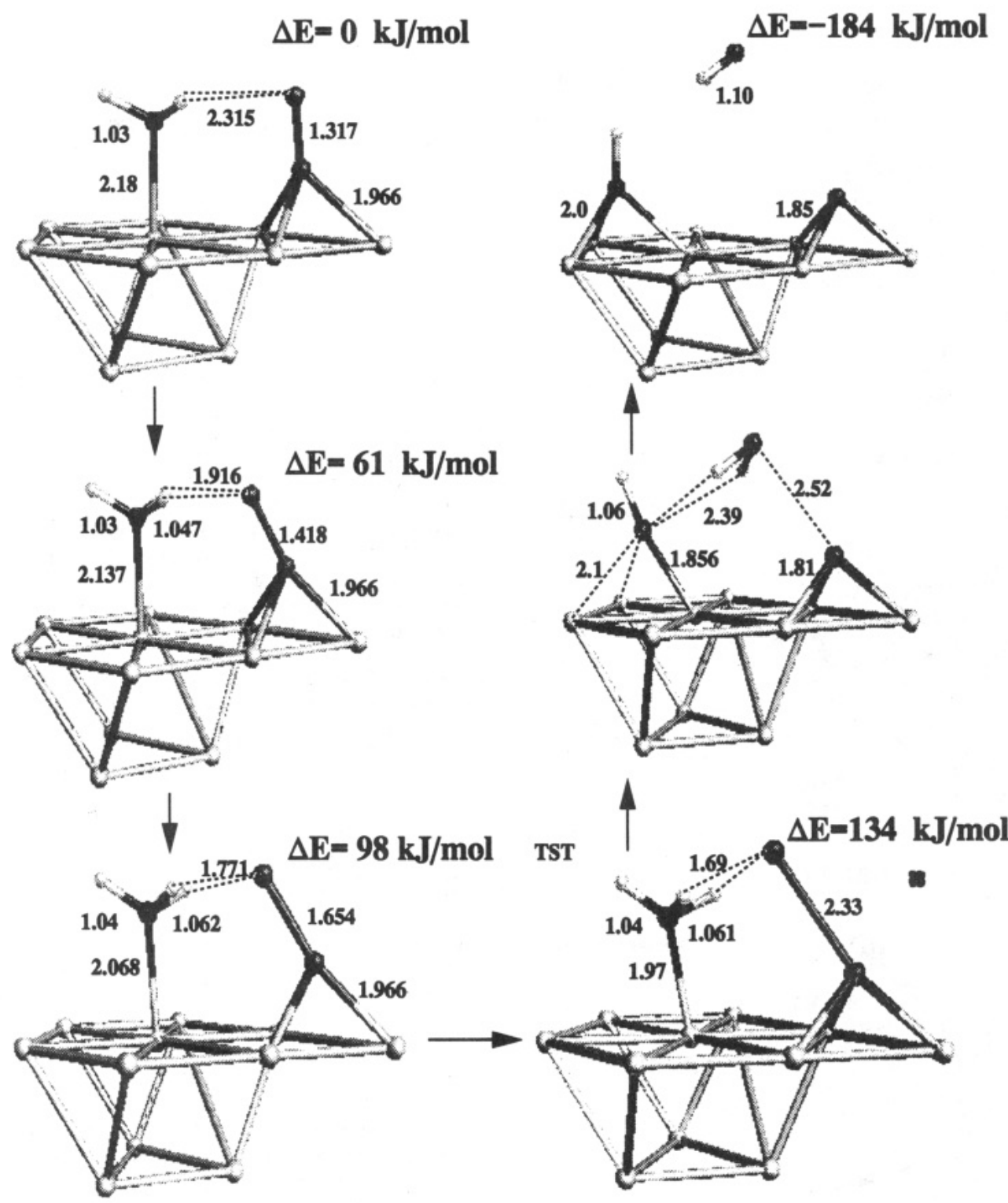

Figure 10. Reaction coordinate calculations for the path 4 dissociation of ammonia over $\mathrm{Cu}(8,3)$. Molecular oxygen acts to abstract a two hydrogen from the coadsorbed ammonia to form $\mathrm{NH}^{*}, \mathrm{O}^{*}$, and gaseous water. The $\mathrm{O}-\mathrm{O}$ stretch is taken as the reaction coordinate. $\Delta E$ is the change in energy with respect to the initial adsorbed state and is reported in $\mathrm{kJ} / \mathrm{mol}$. Bond lengths are in $\AA$.

$\mathrm{Cu}(111)$ is an activated process with a barrier of $8-17 \mathrm{~kJ} / \mathrm{mol}$. Molecular oxygen-ammonia dissociation is therefore the favored route. All of these results directly correspond to the experimental evidence from Roberts ${ }^{14}$ who demonstrated that ammonia readily dissociates in the presence of coadsorbed oxygen and confirm the role of a transient oxygen precursor. At higher partial pressures of oxygen the surface essential becomes poisoned by chemisorbed atomic oxygen species and the rate severely inhibited. This is also consistent with Roberts findings. ${ }^{14}$

Finally, the "hot" atomic oxygen mediated mechanism proposed by Roberts ${ }^{14}$ (path 5) which cannot be completely ruled out is somewhat inconsistent with our findings. The scission of the $\mathrm{NH}$ bond by reaction with hot atomic oxygen requires that energy from the transient oxygen be transferred to the NH bond. The time scale for this step, however, is comparable with that required for thermal equilibration. Thus, the reaction via the molecular precursor path appears more likely.

\section{Conclusions}

Ammonia adsorbs on a model of the $\mathrm{Cu}(111)$ surface at -32 $\mathrm{kJ} / \mathrm{mol}$. In the absence of coadsorbed oxygen species, the

(47) Heras, J. M.; Asensio, M. C.; Visido, L. Z. Phys. Chem. Neue Folge 1988, 160, 199 (estimated adsorption energy). dissociation of ammonia over copper is energetically an unfavorable process with an activation barrier of $+344 \mathrm{~kJ} / \mathrm{mol}$ and an overall reaction enthalpy of $+176 \mathrm{~kJ} / \mathrm{mol}$. In the presence of coadsorbed oxygen species, lateral interactions are important in determining both the adsorption and the activation energies. Atomic oxygen promotes $\mathrm{N}-\mathrm{H}$ bond activation, by lowering the activation energy to $+132 \mathrm{~kJ} / \mathrm{mol}$. The strong atomic oxygen surface bond, however, leads to poisoning of surface sites which inhibits the overall dissociation kinetics. The atomic pathway in which hydrogen is transferred sequentially to form $\mathrm{OH}^{*}$ is favored over the simultaneous path leading to the direct formation of water.

Molecular oxygen adsorbs favorably to $\mathrm{Cu}(111)$ both in parallel and perpendicular orientations to the surface. The parallel mode is a precursor state for $\mathrm{O}_{2}$ dissociation where a significant charge transfer from the surface to $\mathrm{O}_{2} \pi^{*}$ orbital weakens the oxygenoxygen bond as is demonstrated by the long $\mathrm{O}_{2}$ bond (1.43 $\AA$ ). The perpendicular mode, on the other hand, is the precursor state for ammonia dissociation. Coadsorbed molecular oxygen enhances the adsorption of ammonia by $17 \mathrm{~kJ} / \mathrm{mol}$ and acts to lower the barrier for $\mathrm{N}-\mathrm{H}$ bond activation. The sequential hydrogen abstraction pathway, which leads to the $\mathrm{OOH}^{*}$ 


\section{Surface Reactants}

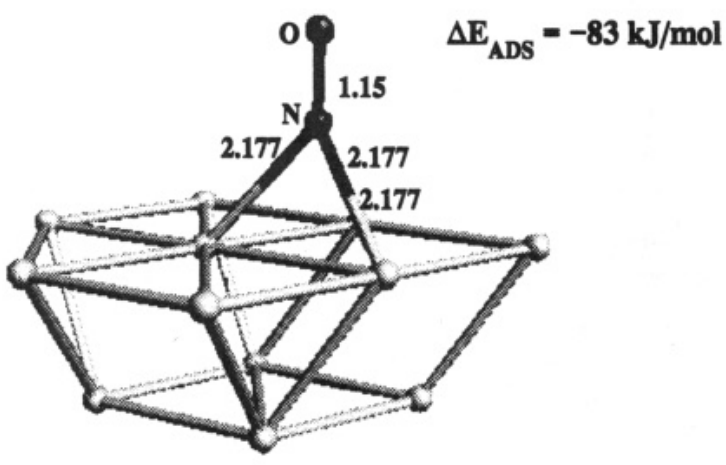

Transition State

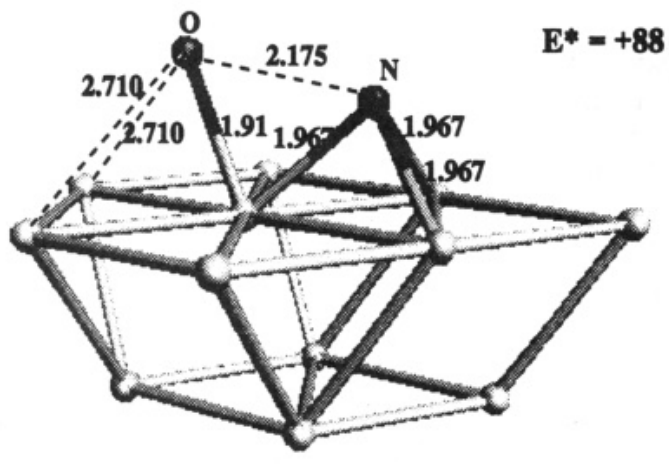

Surface Products

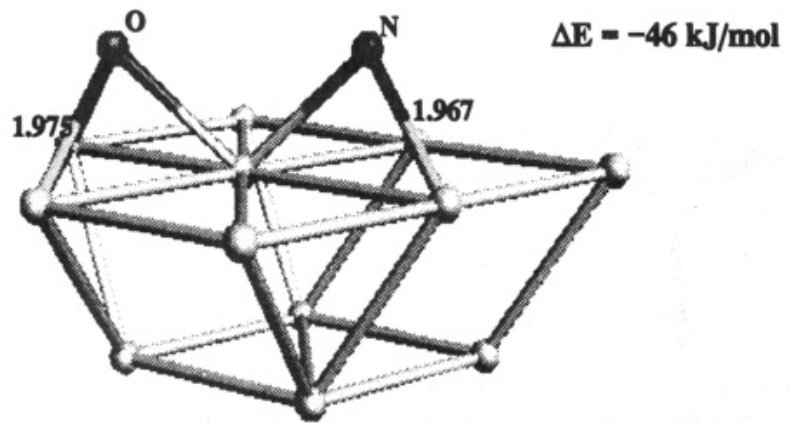

Figure 11. Summary of reaction coordinate calculations for NO dissociation. The surface reactant state refers to the adsorption of NO on $\mathrm{Cu}(8,4)$. The transition state energy and the overall reaction energy are measured with respect to the gas phase, i.e., $\mathrm{NO}(\mathrm{g})$ and clean $\mathrm{Cu}$ $(8,4)$. Bond lengths are reported in $\AA$.

intermediate, while $100 \mathrm{~kJ} / \mathrm{mol}$ less exothermic than the path for the simultaneous hydrogen transfer, is kinetically favored by 67 $\mathrm{kJ} / \mathrm{mol}$.

The sequential-hydrogen-transfer-transient-molecular-oxygen path is the most likely of all those studied. Its apparent activation energy is zero, i.e., a nonactivated process. All paths controlled by transient atomic oxygen, including the not transient oxygen case proposed by Roberts, require at least an initial activation barrier of $+17 \mathrm{~kJ} / \mathrm{mol}$. At low to moderate temperatures the hot atomic oxygen path will be kinetically insignificant in comparison with the molecular path. As the temperature increases, however, these other pathways also become feasible. Chemisorbed atomic

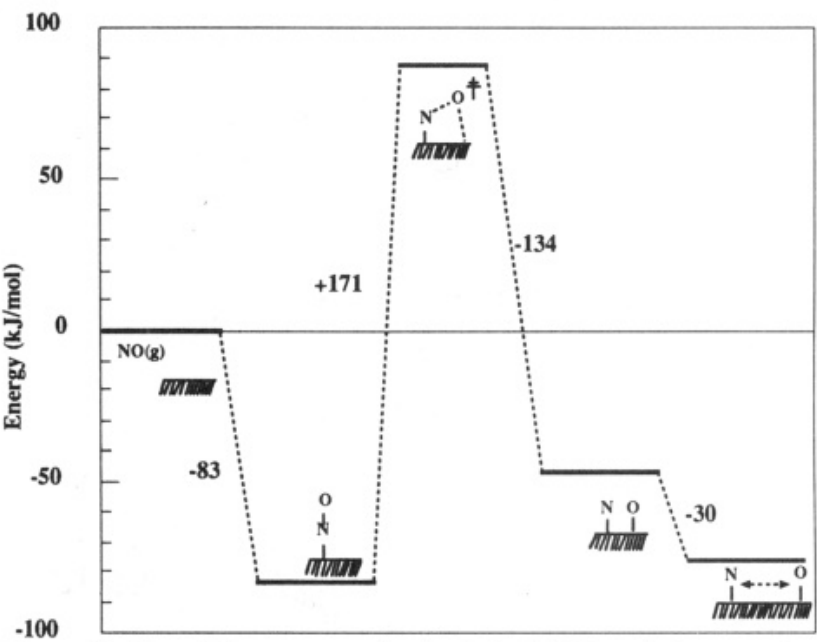

Figure 12. Potential energy reaction path for NO dissociation over $\mathrm{Cu}$ $(8,4)$. The first step is the adsorption of $\mathrm{NO}(\mathrm{g})$. Subsequent steps are the activation barrier for NO dissociation, the intermediate surface products $\left(\mathrm{N}^{*}\right.$ and $\left.\mathrm{O}^{*}\right)$, and the final "diffused" state for low surface coverage systems.

Table 5. Summary of the Activation Energies and the Overall Reaction Energies for Various Paths for the Dissociation of Ammonia

\begin{tabular}{lcc}
\hline \multicolumn{1}{c}{ reaction } & $\begin{array}{c}\text { activation } \\
\text { energy } \\
(\mathrm{kJ} / \mathrm{mol})\end{array}$ & $\begin{array}{c}\text { overall reaction } \\
\text { energy }(\mathrm{kJ} / \mathrm{mol})\end{array}$ \\
\hline $\mathrm{NH}_{3}(\mathrm{~g}) \rightarrow \mathrm{NH}_{2}(\mathrm{~g})+\mathrm{H}(\mathrm{g})$ & +498 & +498 \\
$\mathrm{NH}_{3}{ }^{*} \rightarrow \mathrm{NH}_{2}{ }^{*}+\mathrm{H}^{*}$ & +344 & +176 \\
$\mathrm{NH}_{3}{ }^{*}+\mathrm{O}^{*} \rightarrow \mathrm{NH}_{2}{ }^{*}+\mathrm{OH}^{*}$ & +132 & +48 \\
$\mathrm{NH}_{3}{ }^{*}+\mathrm{O}^{*} \rightarrow \mathrm{NH}^{*}+\mathrm{H}_{2} \mathrm{O}(\mathrm{g})$ & $>204$ & +92 \\
$\mathrm{NH}_{3}{ }^{*}+\mathrm{O}_{2}{ }^{*} \rightarrow \mathrm{NH}_{2}{ }^{*}+\mathrm{OOH}^{*}$ & +67 & -84 \\
$\mathrm{NH}_{3}{ }^{*}+\mathrm{O}_{2}{ }^{*} \rightarrow \mathrm{NH}^{*}+\mathrm{O}^{*}+\mathrm{H}_{2} \mathrm{O}(\mathrm{g})$ & +134 & -184 \\
\hline
\end{tabular}

oxygen is formed, which in turn inhibits ammonia dissociation kinetics. At high enough temperatures or coverages the dissociation reaction eventually shuts down due to the formation of strong chemisorbed oxygen overlayers.

Finally, based solely on overall enthalpy, the recombination of nitrogen adatoms and desorption of $\mathrm{N}_{2}$ was found to be favored over the recombinative removal of NO. However, under reaction conditions both the entropy and the selective collision frequency favor NO formation.

Acknowledgment. We thank Professor E. J. Baerends and his colleagues at the Free University of Amsterdam for their invaluable technical input and the use of the ADF program and G. J. C. S. van de Kerkhof and Dr. P. R. Davies for their initial efforts on this project. This work was supported by the Dutch Science Foundation (Stimulus project) and Eindhoven University of Technology. We kindly acknowledge the computational resources allocated from the National Computing Facilities (NCF) Foundation under project SC-183.

Supplementary Material Available: Tables of exponential coefficients for ADF basis and fit functions (1 page). This material is contained in many libraries on microfiche, immediately follows this article in the microfilm version of the journal, and can be ordered from the ACS; see any current masthead page for ordering information. 